\title{
Multicomponent physical exercise with simultaneous cognitive training to enhance dual-task walking of older adults: a secondary analysis of a 6-month randomized controlled trial with I-year follow-up
}

\author{
This article was published in the following Dove Press journal: \\ Clinical Interventions in Aging \\ 28 October 2015 \\ Number of times this article has been viewed
}

\section{Patrick Eggenberger' \\ Nathan Theill ${ }^{2,3}$ \\ Stefan Holenstein' \\ Vera Schumacher 4,5 \\ Eling D de Bruin ${ }^{1,6,7}$}

'Department of Health Sciences and Technology, Institute of Human Movement Sciences and Sport, ETH Zurich, ${ }^{2}$ Division of Psychiatry Research, ${ }^{3}$ Center for Gerontology, ${ }^{4}$ Department of Gerontopsychology and Gerontology, ${ }^{5}$ University Research Priority Program "Dynamics of Healthy Aging”, University of Zurich, Zurich, Switzerland; 'Department of Epidemiology, CAPHRI School for Public Health and Primary Care, ${ }^{7}$ Centre for Evidence Based Physiotherapy, Maastricht University, Maastricht, the Netherlands
Correspondence: Patrick Eggenberger Institute of Human Movement Sciences and Sport, ETH Zurich, WolfgangPaulistrasse 27, HIT J 32, CH-8093

Zurich, Switzerland

Tel +4I 4463240 I8

Fax $+4 \mid 44632$ II 42

Email patrick.eggenberger@hest.ethz.ch
Background: About one-third of people older than 65 years fall at least once a year. Physical exercise has been previously demonstrated to improve gait, enhance physical fitness, and prevent falls. Nonetheless, the addition of cognitive training components may potentially increase these effects, since cognitive impairment is related to gait irregularities and fall risk. We hypothesized that simultaneous cognitive-physical training would lead to greater improvements in dual-task (DT) gait compared to exclusive physical training.

Methods: Elderly persons older than 70 years and without cognitive impairment were randomly assigned to the following groups: 1) virtual reality video game dancing (DANCE), 2) treadmill walking with simultaneous verbal memory training (MEMORY), or 3) treadmill walking (PHYS). Each program was complemented with strength and balance exercises. Two 1-hour training sessions per week over 6 months were applied. Gait variables, functional fitness (Short Physical Performance Battery, 6-minute walk), and fall frequencies were assessed at baseline, after 3 months and 6 months, and at 1-year follow-up. Multiple regression analyses with planned comparisons were carried out.

Results: Eighty-nine participants were randomized to three groups initially; 71 completed the training and 47 were available at 1 -year follow-up. DANCE/MEMORY showed a significant advantage compared to PHYS in DT costs of step time variability at fast walking $(P=0.044)$. Training-specific gait adaptations were found on comparing DANCE and MEMORY: DANCE reduced step time at fast walking $(P=0.007)$ and MEMORY reduced gait variability in DT and DT costs at preferred walking speed (both trend $P=0.062$ ). Global linear time effects showed improved gait $(P<0.05)$, functional fitness $(P<0.05)$, and reduced fall frequency $(-77 \%$, $P<0.001)$. Only single-task fast walking, gait variability at preferred walking speed, and Short Physical Performance Battery were reduced at follow-up (all $P<0.05$ or trend).

Conclusion: Long-term multicomponent cognitive-physical and exclusive physical training programs demonstrated similar potential to counteract age-related decline in physical functioning.

Keywords: elderly, dance video game, gait, falls, functional fitness, detraining, sex

\section{Introduction}

Falls are a significant health problem in the elderly population. About one-third of people aged 65 years or more fall at least once a year, and incidence rises with aging. ${ }^{1-3}$ Physical injuries from falls in elderly persons often lead to disability and loss of independence and may increase the risk of premature death. Psychological consequences include depression and fear of falling, which are factors that also elevate the risk of falls in the future. ${ }^{4,5}$ Furthermore, considerable health care costs result from 
falls, summing up to US\$23.3 billion annually in the USA and US\$1.6 billion in the UK. The costs per fall associated with injury range from US\$3,476 to US\$10,749 and rise up to US\$26,483 when hospitalization is necessary. ${ }^{6}$ Several risk factors exist for falls, comprising impaired balance and gait, multimedication, a history of previous falls, advancing age, female sex, visual impairments, cognitive decline, and environmental factors. ${ }^{7}$ Stenhagen et $\mathrm{al}^{8}$ found three main components that predict falls: reduced mobility (odds ratio $[\mathrm{OR}]=2.12)$, heart dysfunction $(\mathrm{OR}=1.66)$, and functional impairment $(\mathrm{OR}=1.38)$, whereby each component is related to physical fitness. Hence, many programs try to improve physical fitness and gait with the aim of preventing falls in older adults. $^{9}$

Physical exercise programs were shown to have similar effects on fall prevention as interventions aiming at multiple fall risk factors. ${ }^{10,11}$ A recent meta-analysis among elderly persons living in the community reported significantly reduced fall rate (rate ratio $=0.71$ ) and risk of falling (relative risk $=0.85$ ) after physical multicomponent group exercise. ${ }^{10}$ It was suggested that multicomponent exercise programs should particularly include strength, balance, gait, and coordination training and should last $>12$ weeks (one to three sessions per week) to effectively reduce falls. ${ }^{10,12-14}$ However, a meta-analysis by Muir et $\mathrm{al}^{15}$ reported that fall risk in community-dwelling older adults was elevated considerably when global measures of cognition were impaired (summary estimate of OR $=2.13$ ). Therefore, the efficacy of physical exercise programs in preventing falls may be raised further by adding cognitive training components. In fact, various cognitive domains, including attention, executive function, information processing, and reaction time, are related to balance, gait, and fall risk. ${ }^{15-17}$ Thereby, dual-task (DT) ability, as a part of the executive functions, appears to be especially important.

Regardless of these findings, cognitive aspects are often neglected in fall prevention programs, and to date, few studies have applied multicomponent exercise programs with additional cognitive training to improve DT ability in older persons. Van het Reve and de Bruin, ${ }^{18}$ for instance, reported improvements in DT walking after 12 weeks of balance and strength exercise with sequential computerized cognitive training. Other studies applied cognitive and physical training simultaneously in order to target DT ability more specifically. ${ }^{19-22}$ Although three of these studies successfully improved measures of DT walking, ${ }^{19-21}$ none assessed long-term retention of gait performance and effects on fall frequency. Nevertheless, simultaneous cognitive-physical
DT exercise appears to be promising in complementing multicomponent physical exercise interventions to further enhance DT walking and prevent falls in the elderly persons. However, clearly more extensive research is necessary to substantiate this assumption.

This study aims to compare two variations of multicomponent simultaneous cognitive-physical training with an exclusive physical program and to evaluate the effects of these programs primarily on DT gait performance in healthy elderly persons, whereas fall frequency and functional fitness represent secondary outcomes. We hypothesize, first, that simultaneous cognitive-physical training may create additional enhancements on DT gait variables, and second, that the two cognitive-physical training variations may lead to differential gait adaptations. Based on previous findings, reported earlier, we expect improvements in gait, functional fitness, and a reduction in falls after all the three programs. Furthermore, we aimed to investigate performance retention in gait and functional fitness 1 year after the training interventions. This study is a secondary analysis of a 6-month randomized controlled trial with a 1-year follow-up, where we initially investigated training effects on cognitive performance. $^{23}$

\section{Materials and methods Study design and participants}

This study was a randomized controlled trial, including three groups that underwent parallel 6-month training interventions and a 1-year nonintervention follow-up. Assessments were performed four times: pretraining, after 3 months, 6 months of training (posttraining), and at 1-year follow-up. Data collection and training were performed at Geriatrische Klinik, St Gallen, Switzerland. The study protocol was approved through the local ethics committee of the canton $\mathrm{St}$ Gallen, Switzerland (study number: EKSG 12/092) and was registered at Current Controlled Trials ISRCTN70130279. No changes were made to the planned methods after trial commencement. Our reports adhere to the CONSORT (Consolidated Standards of Reporting Trials) 2010 guidelines. ${ }^{24}$

Participants were recruited through a newspaper article, a local organization for the elderly, ${ }^{25}$ residence facilities for the elderly, primary care physicians, and via the Web sites of the city's geriatric hospital ${ }^{26}$ and the department of sports of the canton St Gallen. ${ }^{27}$ Interested persons were invited to an information event. For eligibility, participants had to be older than 70 years, live independently or at residence facilities for the elderly, and sign informed consent. Participants had to be able to walk at least $20 \mathrm{~m}$, with or without walking aids, 
for gait analysis. Residents of retirement homes classified 0,1 , or 2 within the Swiss classification system for health care requirements (BESA levels, German abbreviation for: Bewohner-Einstufungs- und Abrechnungssystem) could enroll in the study. Level 0 means the person does not need care or treatment and levels 1-2 mean that the person only needs little care or treatment. Seniors diagnosed with Alzheimer's disease, dementia, recent head injury, or a score $<22$ points ${ }^{28}$ on the Mini-Mental State Examination, ${ }^{29}$ which indicates cognitive impairment, were excluded. Judgment by their primary care physician was required in the case of acute or instable chronic diseases (eg, stroke and diabetes) and rapidly progressing or terminal illnesses before accepting a person for participation.

A priori power analysis $\left(G^{*}\right.$ Power 3.1.3 Software $\left.^{30}\right)$ revealed that a total of 75 participants were needed to achieve $80 \%$ power for a three-group pretest, 3 -month and 6-month test design (25 participants per group). The $\alpha$-level was set at 0.05 and the effect size $f$ was set at 0.3 . The randomization scheme was generated with the Web site Randomization. $\underline{\mathrm{com}},{ }^{31}$ applying block randomization to achieve three groups with a ratio of $1: 1: 1$. Participants were blinded to the expected study outcome, while blinding of the investigators was not possible since they supervised and conducted training and testing sessions.

\section{Training programs}

Two 1-hour training sessions per week were performed in groups of five to six participants, under instruction of two trained postgraduate students. At least 1 day was implemented between sessions for recovery. Training programs were based on current recommendations for physical fitness and fall prevention for the elderly persons. ${ }^{12,32,33}$ The three multicomponent programs consisted of 20 minutes aerobic endurance training (video game dancing [DANCE], treadmill memory training [MEMORY], or treadmill walking [PHYS]) and complementary strength and balance exercises (20 minutes each). The training components are described in detail in the following sections, and an overview is provided in Table 1 . The exercise training principles of progression and overload were applied for every training component ${ }^{34}$ and were adapted to each participant's abilities in terms of treadmill speed and inclination, step frequency in DANCE, or number of sets and repetitions, in order to achieve moderate-to-vigorous exercise

Table I Description of training contents according to the FITT principles

\begin{tabular}{lll}
\hline Frequency & Intensity & Time \\
\hline Two sessions & Moderate to vigorous & $20 \mathrm{~min}$ \\
of I hour/wk & (RPE 5-7 points on & \\
(26 weeks) & ten-point Borg-scale) &
\end{tabular}

20 min

Type

Aerobic endurance with (DANCE, MEMORY) or without (PHYS) cognitivemotor coordination aspect:

DANCE: virtual reality video game dancing. 2-3 min/game/song, I-2 min rest periods only if required

or

MEMORY: continuous flat or inclined treadmill walking with simultaneous verbal memory training

or

PHYS: continuous flat or inclined treadmill walking (or running)

$20 \min$

Muscular strength (complement to each intervention):

Examples of lower body exercises: seated leg extensions with $2 \mathrm{~kg}$ ankle weights, chair rises, split leg squats, calf raises (all with or without $5-10 \mathrm{~kg}$ weight vest), standing toe raises; two exercises per session

Examples of upper-body exercises: standing arm row, biceps curls (both with resistive rubber bands), standing wall push-ups. knee push-ups; I-2 exercises per session

Examples of trunk stabilization exercises: incline seated single-leg raises, crunches, front plank; I-2 exercises per session

One to three sets with eight to 12 repetitions, progressing from slow to fast movement speed, $\sim$ I min rest between sets

$20 \mathrm{~min}$

Balance (complement to each intervention):

Examples: tandem stand, two-leg stand on foam pad, walking over a skipping rope on the floor, single-leg stand on air pad, single-leg stand with eyes closed Two to four sets of four to five different exercises per session, 20-60 s per exercise, $\sim 30-60$ s rest

Notes: Training programs were created based on current recommendations for physical fitness and fall prevention for the elderly persons. Data from Sherrington et al, ${ }^{12}$ Granacher et al, ${ }^{33}$ and Nelson et al. ${ }^{63}$

Abbreviations: DANCE, virtual reality video game dancing; FITT, frequency, intensity, time, and type of exercise; MEMORY, treadmill walking with simultaneous verbal memory training; PHYS, treadmill walking; RPE, rate of perceived exertion. 
intensity. This level of intensity corresponds to a subjective rate of perceived exertion of 5-7 points on the 10-point Borg scale as recommended by the American College of Sports Medicine position stand on exercise with older adults. ${ }^{32}$ In total, 52 sessions were conducted within 6 months (26 weeks), with some participants missing certain sessions due to personal reasons. Sessions 25-32 (4 weeks) were conducted individually according to a home exercise plan, due to the Christmas holidays and 3-month test sessions. The home exercise plan comprised the same strength and balance exercises as instructed during normal training sessions, but no DANCE and MEMORY training. Compliance to the home exercise plan was assessed with a training diary.

\section{Video game dancing}

The program DANCE included virtual reality video game dancing as a simultaneous cognitive-physical training (Figure 1A). This training component combines an attention-demanding cognitive action with a simultaneous motor coordination aspect. We used two Impact Dance Platforms (Positive Gaming BV, Haarlem, the Netherlands) and created various levels of difficulty in step patterns and frequency with the StepMania Software. ${ }^{35}$ Several styles of music were selected to add variety and meet preferences of participants. Participants stood on the $1 \times 1 \mathrm{~m}^{2}$ platform, which contained four pressure sensitive areas to detect steps forward, backward, to the left, and to the right, respectively. Stepping sequences were cued with arrows appearing on a large screen and had to be performed exactly when an arrow reached a highlighted area on the screen in order to achieve best scores in the game. Participants were instructed to hold on to ropes for security reasons.

\section{Treadmill memory training}

The program MEMORY comprised treadmill walking with verbal memory exercise as a simultaneous cognitivephysical training (Figure 1B). Verbal memory training consisted of a computer-based serial position training that was presented on a computer screen in front of the treadmill, with a standard computer mouse as an input device. E-Prime 2.0 Professional software (Psychology Software Tools, Pittsburgh, PA, USA) was used to program the training. Participants were asked to memorize the correct sequence of 3-20 words lighting up one after the other for 3 seconds on the computer screen. Thereafter, a distraction task followed, where participants had to define whether three presented words had a meaning or not. Then, the initially memorized words were presented again, either in the same or a different sequence, and participants had to decide whether the sequence remained the same or not, by pressing the mouse button. The initial level for this training was set at a sequence of three words and was extended by one word as soon as the participants reached $80 \%$ of correct answers within the level.

\section{Treadmill walking}

The program PHYS included aerobic treadmill walking without any additional cognitive task and acted as a reference group with exclusive physical training components. Participants were instructed to walk or run at a constant pace.
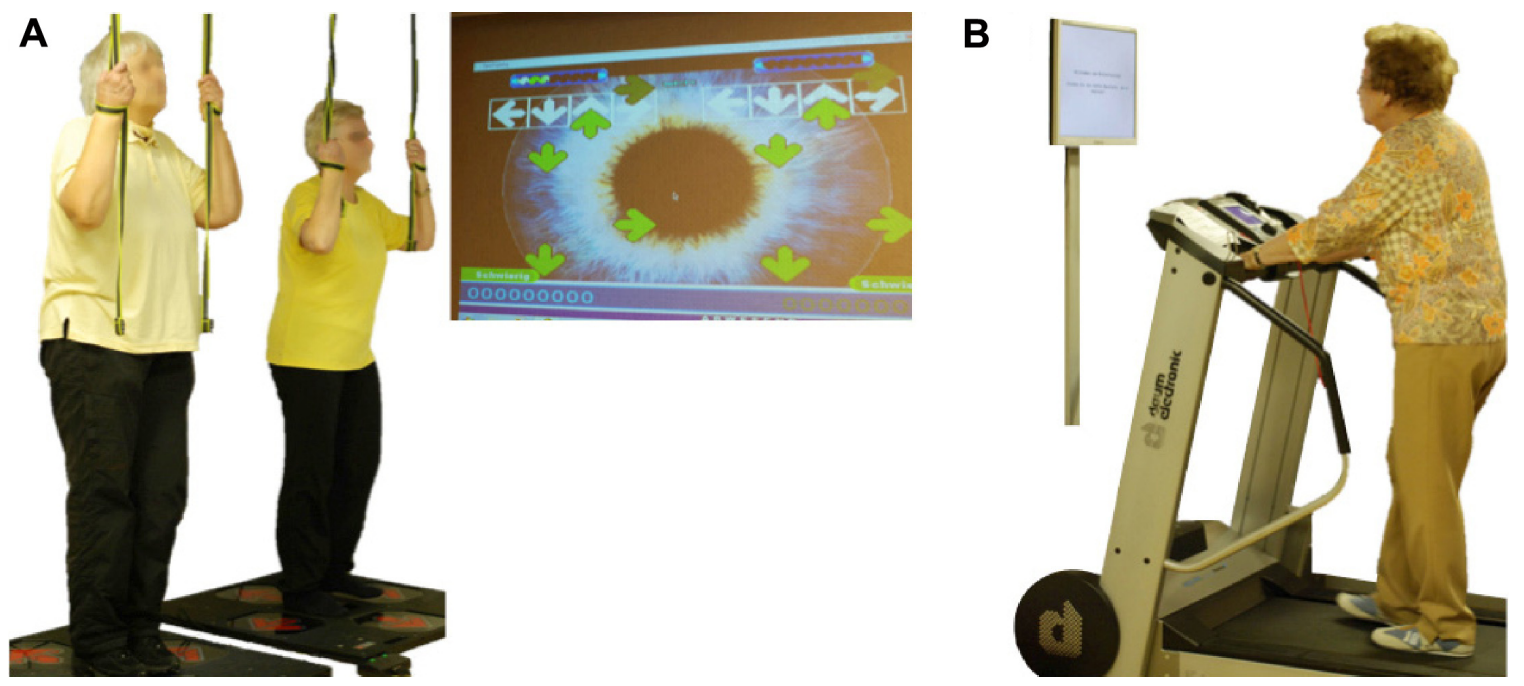

Figure I Simultaneous cognitive-physical training components: video game dancing $(\mathbf{A})$ and treadmill memory training (B).

Notes: In (A), two participants perform steps on a pressure sensitive platform to the rhythm of the music. Step timing and direction are cued with arrows on a screen. In (B), a participant is walking on a treadmill while performing verbal memory exercises presented on a computer screen. 


\section{Complementary strength and balance exercises}

In addition to one of the three different aerobic training components described previously, muscular strength and balance exercises complemented each program (Figure 2). Four to five strength exercises for lower and upper extremities and trunk stabilization were performed using own body weight, resistive rubber bands, and weight vests of maximum of $10 \mathrm{~kg}$. Balance training consisted of different exercises including two- and single-leg stance variations, either on the floor or on various types of instable surfaces (eg, foam and air pads, ropes, etc)..$^{36}$

\section{Measurements}

\section{Gait analysis (primary outcome)}

Temporal and spatial gait variables were assessed using the GAITRite electronic walkway system (CIR Systems, Havertown, PA, USA) with the Platinum Version 4.0 software. The validity and reliability of the GAITRite system have been well established. ${ }^{37-39}$ Walking was initiated $2 \mathrm{~m}$ before the $7.3 \mathrm{~m}$ active area of the walkway and ended $2 \mathrm{~m}$ thereafter to allow for steady-state gait assessment. The testing protocol comprised four conditions, which were singletask (ST) and DT walking at the individual's preferred and fast speed. Each test condition was repeated three times, and the mean value was used for further analysis. Trials were repeated when a participant stopped walking or performing the cognitive task. The cognitive-motor DT condition was adjusted to the participant's cognitive abilities and included walking while counting backward in steps of seven or three from a random number between 200 and 250 or enumerating objects (eg, flowers, country names, or first names). The purpose of this procedure was to quantify cognitive-motor interference while walking. ${ }^{40}$ Participants were instructed not to prioritize either task and were allowed to use assistive walking devices. Relative dual-task costs (DTCs) of walking, as the percentage of relative loss to the ST walking performance, were calculated according to the formula DTC $=100 \times$ (dual-task score - single-task score)/single-task score.

\section{Secondary outcomes}

Fall frequency was assessed retrospectively for the 6-month period prior to the intervention, after 3 months and 6 months of training, and 6 months and 12 months after the intervention. Participants who were not available for the 6-month and 1-year follow-up events were interviewed via telephone at the respective time points.

The Short Physical Performance Battery (SPPB) was used to assess lower extremity functioning with a balance test, a $3 \mathrm{~m}$-walk test, and a five chair-rises test. ${ }^{41}$ Full criteria for test administration are available at the National Institute
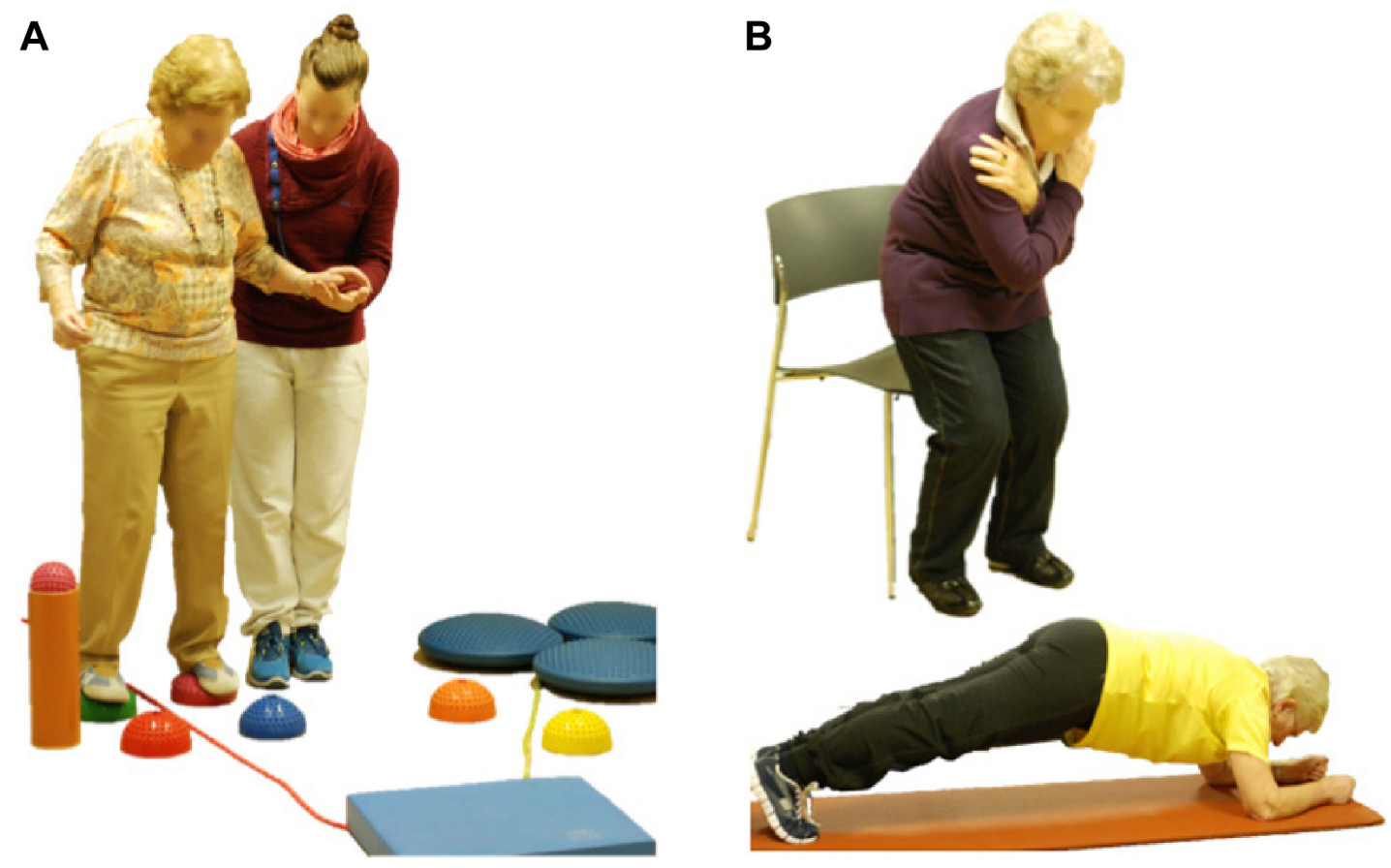

Figure 2 Examples of complementary balance $(\mathbf{A})$ and strength $(\mathbf{B})$ exercises.

Notes: The participant in (A) steps from one object to the next, trying to maintain balance under assistance of an instructor (objects are soft rubber "stones", skipping ropes, and balance pads). (B) Shows one participant performing chair rises (squats) and another participant holding the "plank" position for global trunk stability, which was an exercise for the elderly with higher fitness level. 
on Aging Web site. ${ }^{42}$ We extended the standard SPPB balance test with two additional levels to increase difficulty and to avoid possible ceiling effects. The first additional level comprised a 20-second single-leg stance. One point was added when 10 seconds were reached and another point when 20 seconds were completed. In the second additional level, a single-leg stance with eyes closed was required to be maintained as long as possible. One point was added to the balance score for every 5 seconds the position was held.

Functional aerobic endurance performance was measured with the 6-minute walk test (6-MWT) following the guidelines of the American Thoracic Society. ${ }^{43}$ Participants were asked to walk as far as possible on a $30 \mathrm{~m}$ walking course within 6 minutes. This test was not repeated at follow-up to reduce the test time for participants. Maximum walking distance and rate of perceived exertion were recorded immediately after completion of the test. Ratings of perceived exertion were assessed by means of the ten-level Category Ratio Scale (adapted Borg scale). ${ }^{44}$

The Falls Efficacy Scale International (FES-I) was applied as a measure of fear of falling, ${ }^{45}$ while symptoms of depression were recorded using the German version of the Geriatric Depression Scale (GDS). ${ }^{46}$

\section{Statistical analyses}

Group differences in the baseline demographic and performance data were compared with one-way analysis of variance (ANOVA). Multiple regression analysis with planned comparisons, including orthogonal contrast and polynomial trend coding, was applied to investigate the training effects on gait variables and functional fitness for the 6-month training. We produced contrast-coding variables based on the hypotheses. The first contrast was set to compare the two combined cognitive-physical training groups with PHYS. The second contrast compared the two cognitive-physical training groups (DANCE vs MEMORY). Effect code variables were produced for each group's individuals to account for subject effects. Repeated-measures ANOVA were used to assess differences between the 6-month test and the 1-year follow-up, as well as for the supplementary analysis of sex differences. Missing values from participants who completed the full 6-month trial, but missed single-test items due to health constraints or social obligations, were replaced by the group mean value at the respective time point of measurement. Statistical calculations were performed with IBM SPSS Statistics software for Macintosh, Version 22.0 (IBM Corporation, Armonk, NY, USA) with a significance level of $\alpha=0.05$. Effect sizes, represented as $R^{2}$-change in the multiple regression analysis, were considered as small for $R^{2}$-change $=0.01$, medium for $R^{2}$-change $=0.06$, and large for $R^{2}$-change $=0.14$ and above. Effect size $r$ from ANOVA was defined as small at $r=0.10$, medium at $r=0.30$, and large at $r=0.50$ and above. ${ }^{47}$

\section{Results}

Of the 89 participants initially enrolled, 71 participants completed the 6-month training intervention (20.2\% attrition) and were included in the analysis of the outcomes derived at pretest, 3-month, and 6-month tests. Time points and reasons for dropouts are presented in Figure 3. Dropouts were equally distributed between groups, and therefore, the final analyses were performed only in those individuals who completed the 6-month intervention. At 1-year follow-up, 47 participants were available for gait and SPPB measurements, while falls data of 66 persons were recorded and included in the analysis. The following numbers of missing values were replaced by the group mean value: 33 gait, one $3 \mathrm{~m}$-walk, fourteen 6-MWT, and one GDS and FES-I. Participants' recruitment lasted from August 2012 until the end of September 2012, when pretests were performed. The training intervention lasted from October 2012 until the end of March 2013, with follow-up test in April 2014. Table 2 shows baseline demographic characteristics and training compliance of the three intervention groups.

\section{Gait analysis}

Performance data for all gait variables are presented in Table 3. Comparison of baseline performance shows significant differences between intervention groups for two gait variables (step length variability fast-DTC, $P=0.050$; step time variability fast-DTC, $P=0.039)$. Baseline data were not different for the other gait variables ( $P$-values from 0.11 to 0.91 ). Statistical details of the multiple regression analysis over the first three time points of measurement, including two planned comparisons or contrasts, are provided in Tables S1-S5. Linear global time effect showed significant performance improvements in all intervention groups from pretest to 6-month test in 19 of the 20 gait variables (all $P<0.05, R^{2}$ from 0.008 to 0.118 ). In the DTC gait variables, the linear global time effect did not show any significant reductions ( $P$-values from 0.069 to 0.96 ).

In the first contrast of the multiple regression analysis, a significant linear interaction was found in "step time variability fast-DTC" with no change in the two cognitive-physical interventions (DANCE and MEMORY) and rising DTC in PHYS (Figure 4A; $F(1,136)=2.95, P=0.044$, one-tailed, $R^{2}=0.010$ ). 


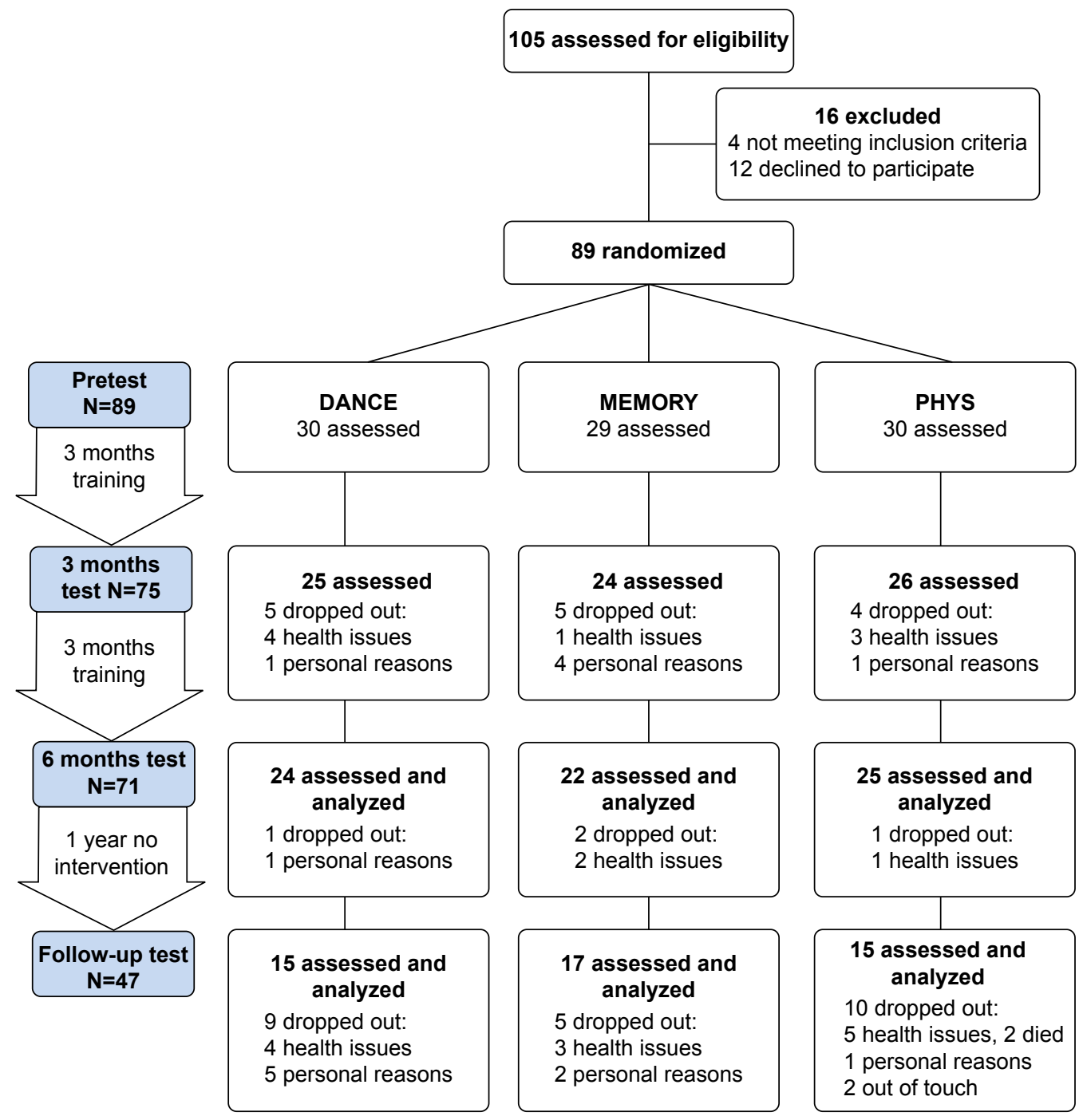

Figure 3 Trial design and participants' flow.

Notes: Participants were randomly assigned to one of the two multicomponent simultaneous cognitive-physical training groups (DANCE and MEMORY) or an exclusive physical exercise group (PHYS) and were trained over 6 months twice weekly for I hour. Gait variables, functional fitness, and fall frequency were assessed at pretest, 3-month and 6-month test, and at I-year follow-up (except 6-MWT not repeated at follow-up). Fall frequency was additionally assessed 6 months after training.

Abbreviations: DANCE, virtual reality video game dancing; MEMORY, treadmill walking with simultaneous verbal memory training; 6-MWT, 6-minute walk test.

Table 2 Baseline demographic characteristics and training compliance

\begin{tabular}{lllll}
\hline Variable & DANCE & MEMORY & PHYS & $\begin{array}{c}\text { P-value, } \\
\text { two tailed }\end{array}$ \\
\hline $\mathrm{N}$ & 24 & 22 & 25 & \\
Sex, female & $14,58.3 \%$ & $16,72.7 \%$ & $16,64.0 \%$ & 0.602 \\
Age, years & $77.3(6.3)$ & $78.5(5.1)$ & $80.8(4.7)$ & $\mathbf{0 . 0 7 9}$ \\
Height, cm & $165.1(7.7)$ & $163.9(8.5)$ & $162.0(8.9)$ & 0.425 \\
Weight, kg & $75.8(12.3)$ & $73.6(9.4)$ & $69.5(14.1)$ & 0.198 \\
BMl, kg/m & $23.0(3.6)$ & $22.4(2.2)$ & $21.4(3.9)$ & 0.259 \\
MMSE, score & $28.4(1.4)$ & $28.3(1.2)$ & $28.0(1.7)$ & 0.533 \\
Total training compliance & $84.3 \%(12.7 \%)$ & $86.1 \%(9.1 \%)$ & $87.1 \%(7.9 \%)$ & 0.633 \\
(52 sessions) & & & & \\
Home-training compliance & $79.9 \%(23.0 \%)$ & $90.0 \%(14.8 \%)$ & $83.5 \%(18.4 \%)$ & 0.201 \\
(eight sessions) & & & &
\end{tabular}

Notes: Data are means ( \pm standard deviations in brackets) or numbers. Bold values indicate significance or trend. ${ }^{\mathrm{t} P}<0.10$ trend.

Abbreviations: BMI, body mass index; DANCE, virtual reality video game dancing; MEMORY, treadmill walking with simultaneous verbal memory training; MMSE, MiniMental State Examination; PHYS, treadmill walking. 


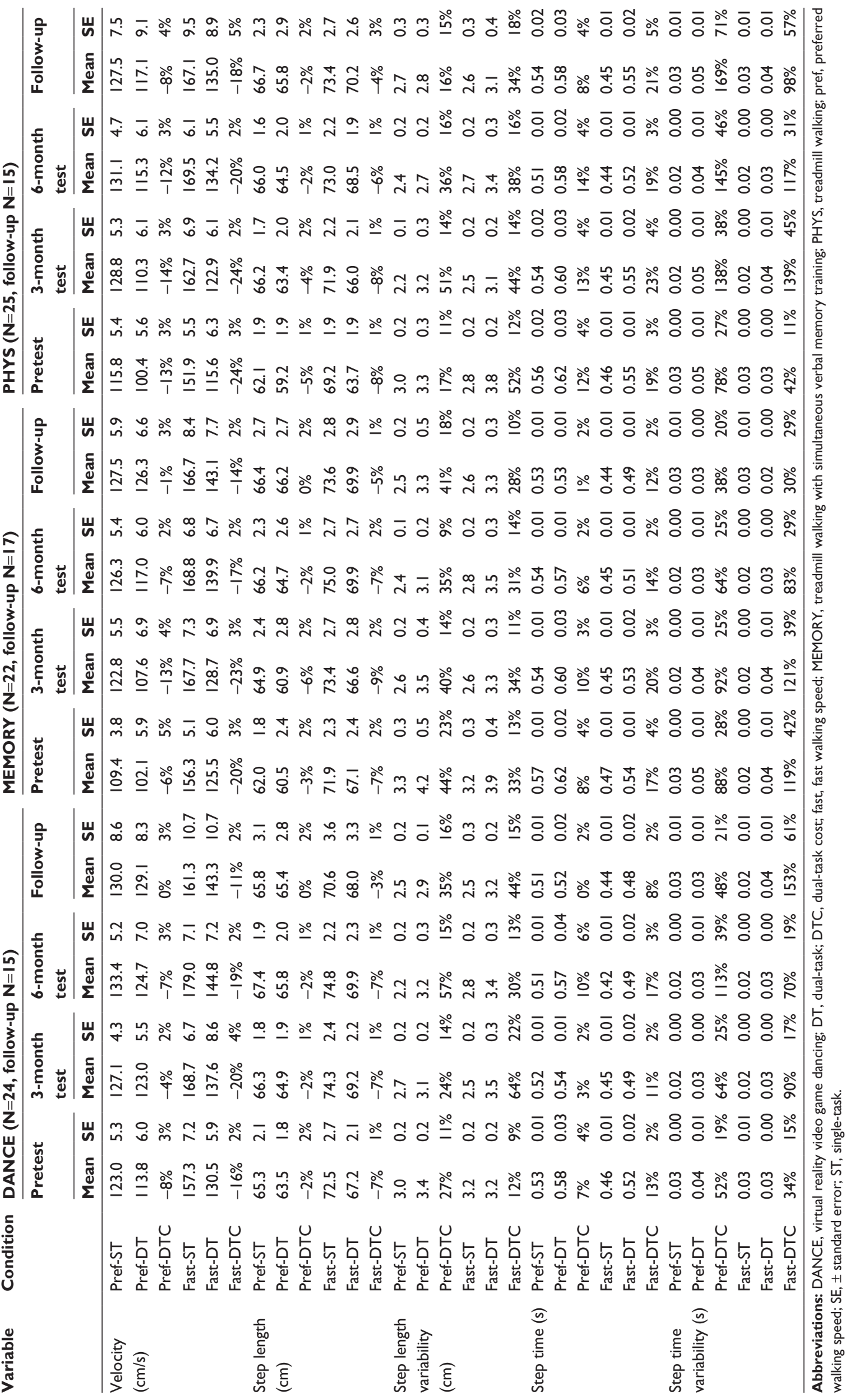




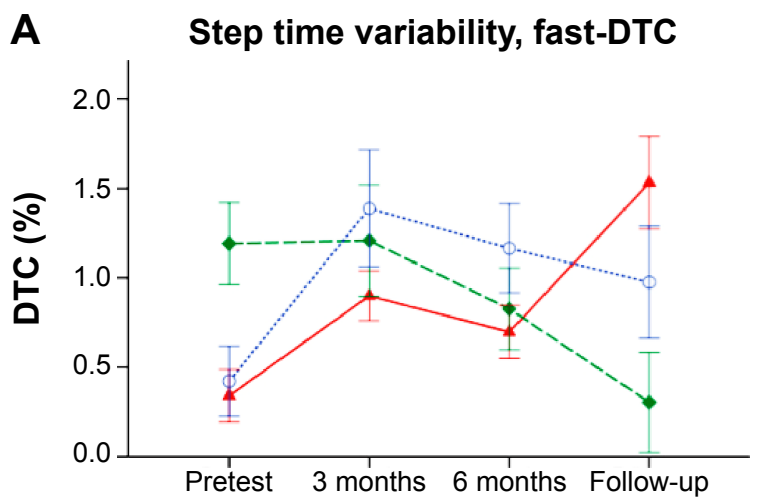

C Step length variability, preferred-DT

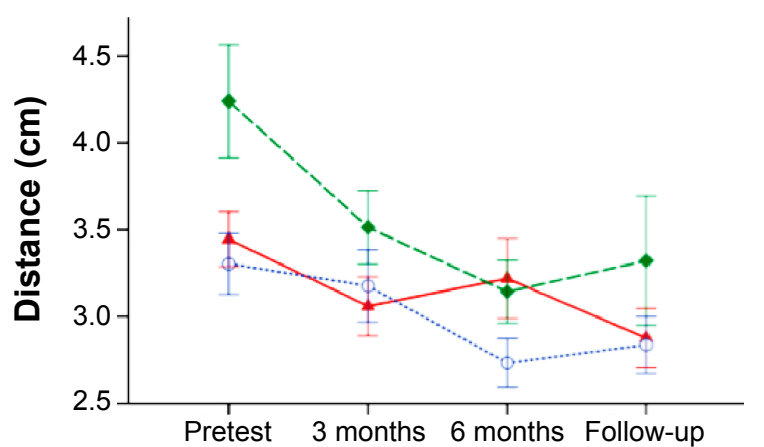

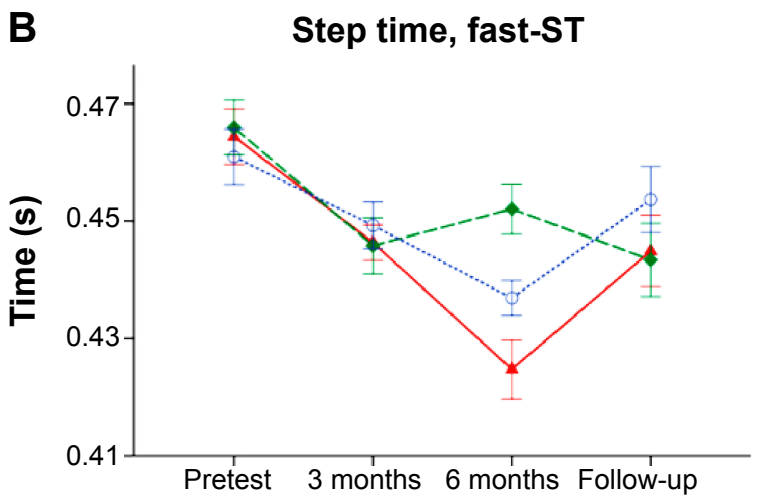

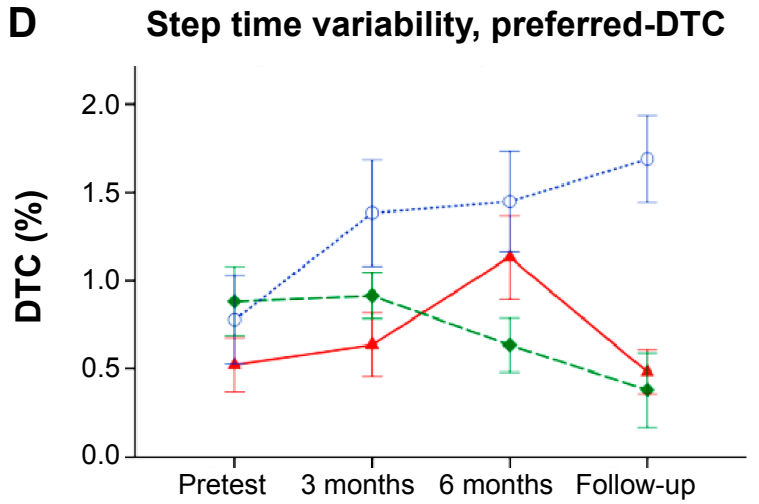

$\rightarrow$ DANCE $\quad-\rightarrow-$ MEMORY $---0--$ PHYS

Figure 4 Development of the gait variables that showed time $\times$ intervention contrasts from pretest to 6-month test.

Notes: (A) Depicts a significant first contrast with unchanged DTC in the two cognitive-physical interventions (DANCE and MEMORY) due to parallel improvements in ST and DT and rising DTC in PHYS due to improvement in ST and no change in DT ( $P=0.044$, one tailed). (B-D) Illustrate significant or trend to significant second contrasts (DANCE versus MEMORY): (B) in favor of DANCE ( $P=0.007$, two tailed) and ( $C$ and $\mathbf{D}$ ) in favor of MEMORY (trend $P=0.062$, two tailed and trend $P=0.062$, two tailed, respectively). Performance from 6 months until I-year follow-up remained unchanged in (A, C, and $\mathbf{D}$; all $P>0.10)$, whereas "step time fast-ST" increased (B; trend $P=0.077$, two tailed). Error bars indicate \pm standard error of the mean.

Abbreviations: DTC, dual-task cost; DANCE, virtual reality video game dancing; MEMORY, treadmill walking with simultaneous verbal memory training; ST, single-task; DT, dual-task; PHYS, treadmill walking.

The second contrast indicated three time $\times$ intervention interaction effects (Figure 4B-D). A significant linear interaction was found for the variable "step time fast-ST", showing continuous improvement in DANCE and maintained performance for MEMORY $(F(1,136)=7.51, P=0.007$, two-tailed, $\left.R^{2}=0.009\right)$. A trend for a significant linear interaction was identified for "step length variability preferred-DT", representing unchanged performance for DANCE and declining variability for MEMORY $(F(1,136)=3.53$, trend $P=0.062$, two-tailed, $\left.R^{2}=0.009\right)$. "Step time variability preferred-DTC" showed another trend for a significant linear interaction with an increase in DANCE and a reduction in MEMORY over the course of the 6-month training $(F(1,136)=3.55$, trend $P=0.062$, two-tailed, $R^{2}=0.011$ ).

Performance remained unchanged from 6 months to follow-up test in 12 of the 20 gait variables, whereas performance in six variables decreased (statistical analyses available in Table S6). The variables "velocity preferred-DT" and "step-time preferred-DT" showed significant improvements $(F(2,44)=7.10, P=0.011$, two-tailed, $r=0.37$ and $F(2,44)=9.36, P=0.004$, two-tailed, $r=0.42$, respectively). DTCs of walking were maintained after 1-year follow-up in four of the ten DTC gait variables and were reduced, significantly or with a trend, in the six other DTC variables.

\section{Fall frequency}

Fall frequency of the three intervention groups is depicted in Figure 5. Baseline data were not different between groups $(P=0.23)$. Multiple regression analysis of the linear global time effect over the first three 6-month periods of fall observation revealed a significant reduction in fall frequency $\left(F(1,126)=12.93, P<0.001\right.$, one-tailed, $\left.R^{2}=0.056\right)$. No differences between interventions were found with planned comparisons (all $P>0.05$ ). Statistical details for the multiple 


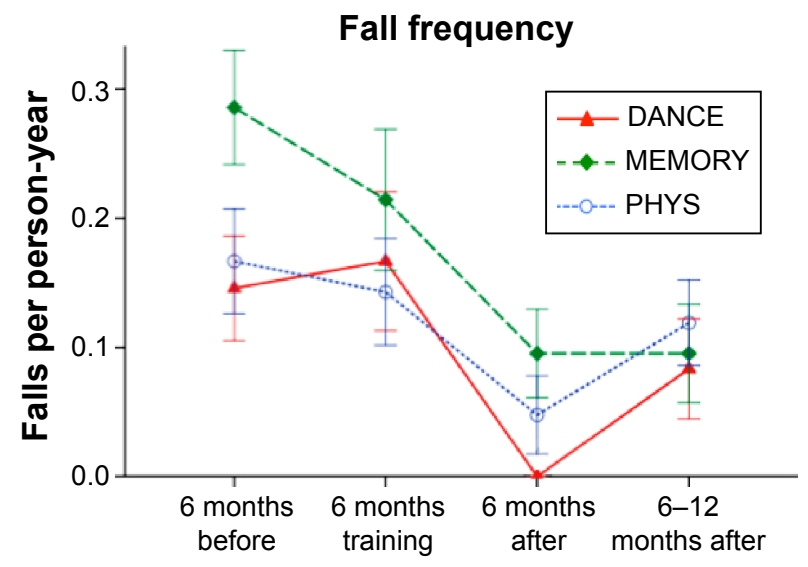

Figure 5 Development of fall frequency over 2 years.

Notes: A significant reduction over the first three 6-month periods $(P<0.00$ I, one tailed) and a subsequent trend for an increase after the fourth period was shown (trend $P=0.059$, two-tailed). Error bars indicate \pm standard error of the mean. Abbreviations: DANCE, virtual reality video game dancing; MEMORY, treadmill walking with simultaneous verbal memory training; PHYS, treadmill walking.

regression analysis are provided in Table S7. A trend was evident for an increase in fall frequency from the 6-month period after training to the period from 6 months to 12 months $(F(1,63)=3.70$, trend $P=0.059$, two-tailed, $r=0.24)$.

\section{SPPB and 6-MWT}

Baseline performance was not different between intervention groups ( $P$-values from 0.61 to 0.99 ). Multiple regression analysis of the linear global time effect showed a significant increase in all functional fitness measures from pretest to 6-month test (all $P<0.001$, one-tailed, $R^{2}$ from 0.023 to $0.141)$. Performance declined significantly from 6 months to follow-up test in SPPB total score $(F(1,44)=5.26, P=0.027$, two-tailed, $r=0.33$ ), while performance in the SPPB subtests
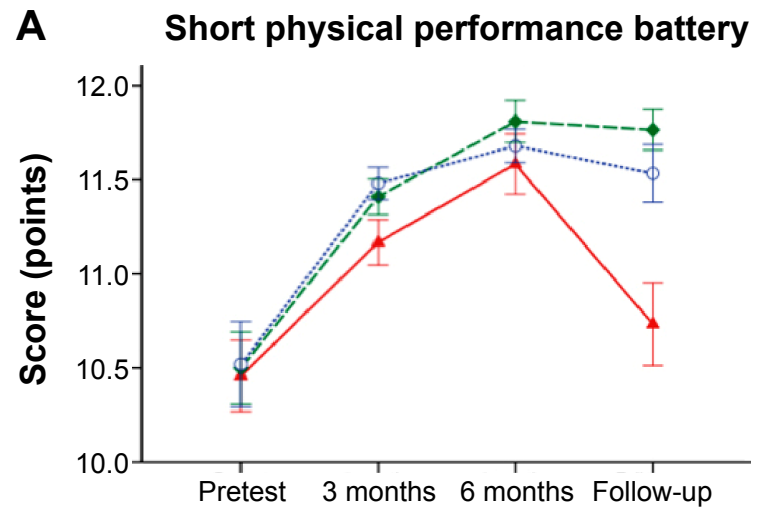

3 m-walk, five chair-rises, and extended balance test was maintained (all $P>0.10$ ). Planned comparisons did not reveal any significant time $\times$ intervention interactions (all $P>0.05$ ). Figure 6 depicts performance development for SPPB total score and 6-MWT distance. Performance data for the functional fitness variables are presented in Table 4, and details of statistical analyses are provided in Tables S8 and S9.

\section{Sex differences}

This supplementary analysis indicated time $\times$ sex interactions in favor of the male participants in the gait variables "velocity fast-ST" (Figure 7A) and "step length fast-ST" $(F(1.83,126.05)=3.20, P=0.049$, two-tailed, $r=0.16$ and $F(1.73,119.08)=2.68$, trend $P=0.080$, two-tailed, $r=0.15$, respectively), as well as in the five chair-rises test (Figure 7B, $F(1.42,97.96)=3.21$, trend $P=0.061$, two-tailed, $r=0.18)$. In the ANOVA for these three variables, Mauchly's test indicated that the assumption of sphericity had been violated $\left(\chi^{2}(2)=6.77,11.77\right.$, and 35.74, respectively, $\left.P<0.05\right)$, therefore, Greenhouse-Geisser tests are reported $(\varepsilon=0.91,0.86$, and 0.71 , respectively). Baseline performance was different between sexes in "velocity fast-ST" (trend $P=0.077$ ) and "step length fast-ST" $(P=0.001)$ but not in five chair-rises $(P=0.68)$. Data without statistical trends or significant interactions are not presented.

\section{GDS and FES-I}

Baseline data were not different between groups in GDS and FES-I ( $P=0.38$ and 0.55 , respectively). Repeated measures ANOVA from pretest to 3- and 6-month tests did not reveal

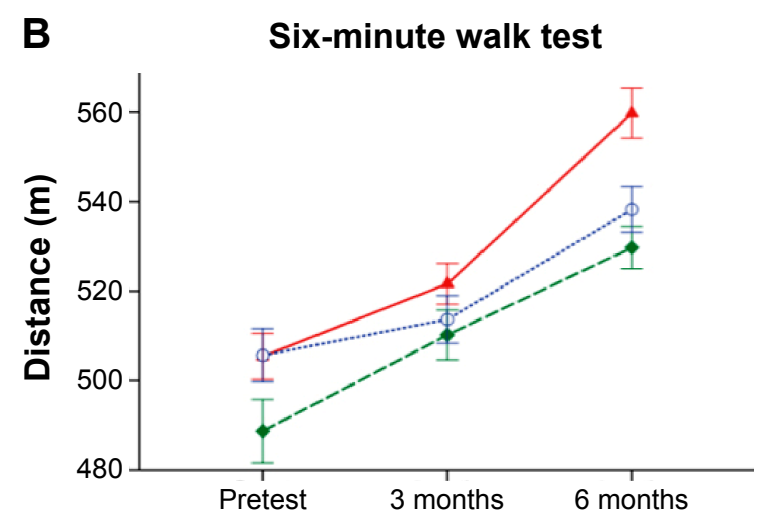

$\multimap-$ DANCE $-\bullet-$ MEMORY -- --- PHYS

Figure 6 Development of functional fitness.

Notes: $(\mathbf{A})$ and $(\mathbf{B})$ illustrate significant enhancements in two functional fitness measures from pretest to 6 -month test $(P<0.00 \mathrm{I}$, one tailed). Additionally $(\mathbf{A})$ shows attenuated performance after I-year follow-up ( $P=0.027$, two-tailed). No differences between interventions were found. Six-minute walk test was not repeated at follow-up. Error bars indicate \pm standard error of the mean.

Abbreviations: PHYS, treadmill walking; DANCE, virtual reality video game dancing; MEMORY, treadmill walking with simultaneous verbal memory training. 


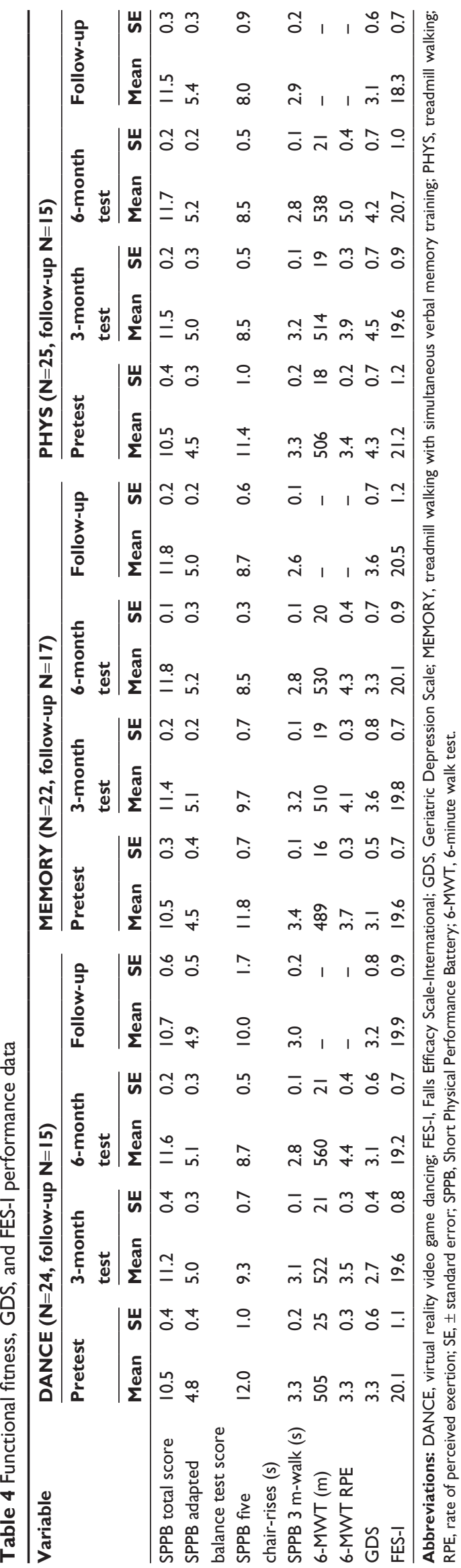

significant changes in both $\operatorname{GDS}(F(1.77,120.16)=0.045$, $P=0.94$, two-tailed $)$ and FES-I $(F(1,136)=1.55, P=0.22$, twotailed). In the ANOVA for GDS, Mauchly's test indicated that the assumption of sphericity had been violated, $\chi^{2}(2)=9.47$, $P<0.05$; therefore, Greenhouse-Geisser tests are reported $(\varepsilon=0.88)$. Similarly, from 6 months to follow-up test, scores in GDS and FES-I remained unchanged $(F(1,44)=0.045$, $P=0.83$, two-tailed and $F(1,44)=1.56, P=0.22$, two-tailed, respectively). Performance data for GDS and FES-I are presented in Table 4.

\section{Discussion}

This study aimed to compare two multicomponent simultaneous cognitive-physical training interventions with an exclusive physical exercise program on their effects on DT walking. The study comprised a 6-month training intervention and a 1-year follow-up. The two main findings were 1) that the two simultaneous cognitive-physical programs resulted in a significant advantage in DTCs of walking compared to the exclusive physical program but not in any other gait variables and 2) that the two simultaneous cognitive-physical interventions led to different trainingspecific adaptations in gait.

\section{Are there advantages of simultaneous cognitive-physical training programs on DT walking?}

This study found one indication of an advantage of the two cognitive-physical programs (DANCE and MEMORY) over PHYS. This significant first contrast was evident in the gait variable "step time variability fast-DTC", whereby unchanged DTC in the two cognitive-physical interventions represented parallel improvements in ST and DT, and in contrast, rising DTC in PHYS resulted due to improvements in ST and no change in the DT walking condition over the 6-month training period. Baseline levels were different between interventions in this variable, but this should not affect the time $\times$ intervention interaction. Hence, this outcome probably reflects improved cognitive-motor DT abilities from simultaneous cognitive-physical training. Nevertheless, it is important to note that the analyses of the first contrast did not reach statistical significance in any other gait variable. Moreover, global linear time effects were significant in almost all gait variables and, therefore, support very similar improvements in the three intervention groups. Similarly, Forte et $\mathrm{al}^{22}$ reported improvements in DT fast walking after both single strength training and multicomponent cognitivephysical training. Their and our own findings support the 

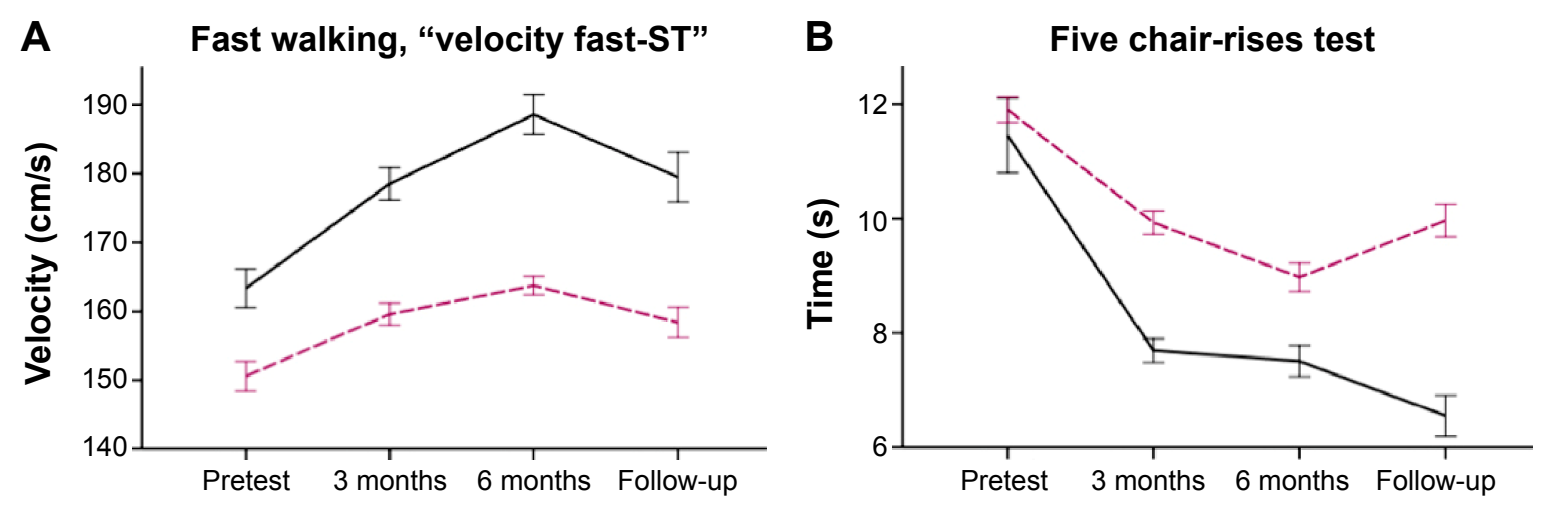

Male =-n- Female

Figure 7 Performance developments for sexes.

Notes: $(\mathbf{A})$ and $(\mathbf{B})$ depict time $\times$ sex interactions from pretest to 6 -month test in favor of the male participants in two measures related to muscular power $(P=0.049$, two tailed and trend $P=0.061$, two tailed, respectively). No significant interaction was found from 6-month test to I-year follow-up. Error bars indicate \pm standard error of the mean. Abbreviation: ST, single-task.

importance of the physical training components in simultaneous cognitive-physical programs for older adults.

Additionally, the results of this study demonstrated that the two simultaneous cognitive-physical training variations led to differential adaptations in gait reflected by the second contrast (DANCE versus MEMORY). DANCE, which promotes fast, rhythmic, and accurate foot movements, improved step time (or cadence) significantly more in the fast walking condition than MEMORY. According to the five-factor model for gait domains suggested by Lord et $\mathrm{al}^{48}$ step time belongs to the "rhythm" domain of gait, with the other domains being pace, variability, asymmetry, and postural control. The five factors are suggested to be associated with selected cognitive and motor characteristics under the assumption that gait is not a unitary concept. ${ }^{45}$ It was reported that gait rhythm is associated with performance in cognitive tests for information processing speed and attention (Stroop reading and Stroop color naming test, and Letter-Digit Substitution Task). ${ }^{49}$ Both these cognitive domains are also part of the video game dance training and, therefore, seem to support the finding of a training-specific adaptation or a transfer to a related gait variable.

Another training-specific adaptation or transfer to gait was found after the MEMORY training. This training represents typical cognitive-motor DT training and specifically reduced variability of step length under the DT condition, as well as DTC of step time variability compared to DANCE. Thereby, in the MEMORY training, treadmill walking itself might have additionally promoted lower gait variability since participants must adapt to the constant treadmill speed. Our assumption is supported by a pilot study, including nine patients with Parkinson's disease, which reported a trend for reduced swing time variability after 6 weeks of ST treadmill walking. ${ }^{50}$
Interestingly, elevated stride length variability is related to lower levels of hippocampal neuronal metabolism in older persons with mild memory impairments. ${ }^{51}$ The hippocampus plays a role not only in locomotion but also in memory and learning, ${ }^{52}$ and reductions in hippocampal volume and metabolism are associated with difficulties in verbal memory in older adults without dementia. ${ }^{53}$ These findings support our notion of a second training-specific adaptation since verbal memory was explicitly practiced in the MEMORY training. This result is of great relevance because gait variability was also suggested to be the most important intermediate gait variable in the relation between cognition and fall risk. ${ }^{1,49}$

To date, no other study has investigated training-specific adaptations or transfers to gait after different simultaneous cognitive-physical training modalities. Nonetheless, in two previous studies, virtual reality video game dancing resulted in increased walking speed in the DT fast walking condition compared to strength and balance training alone ${ }^{20}$ and reduced DTCs of walking compared to a usual care physical training. ${ }^{21}$ However, interpretation of these studies' results is limited since training volume was higher in the video game dancing groups.

\section{Are performance gains in gait maintained?}

Performance in six gait variables was reduced after 1 year without any further training being applied by the investigators. The reduction in gait performance was particularly prominent in the fast-ST walking condition, affecting velocity, step length, step time, and step time variability. Additionally, two gait variability measures were significantly elevated at preferred walking speed (step length variability and step time variability). In contrast, gait performance under preferred 
and DT walking conditions was maintained until 1-year follow-up. This finding may demonstrate retention of more basic fitness parameters, whereas fast walking is physically more demanding and therefore showed an earlier reduction due to detraining. Elevated gait variability may be an early indication of increased fall risk, since it was attributed to be the most important intermediate gait variable in association with cognition and fall risk as mentioned previously. ${ }^{1,49}$ In fact, fall frequency tended to increase in the 6- to 12-month period after training, compared to the previous 6-month period during follow-up.

Nonetheless, maintenance of several gait and functional fitness variables over a relatively long period of 1 year is quite surprising and may be explained by two reasons: 1) the application of a progressive training protocol with sufficient volume and intensity over the 6-month period and 2) some participants continuing to exercise individually during follow-up. This outcome also demonstrates that our interventions successfully motivated and enabled the elderly to keep up training after the intervention. To our knowledge, only one other multicomponent intervention study performed 6 months of training and a 1-year follow-up with older adults. This study ${ }^{54}$ reported similar long-lasting training effects in functional fitness parameters, but some decline in strength measures. In contrast, the few other multicomponent training studies in older persons, which we are aware of, did not successfully maintain physical performance, although applying shorter follow-up periods of 6 weeks ${ }^{55}$ or 3 months, ${ }^{56,57}$ and despite performing quite long interventions of 8 months or 9 months training, ${ }^{56,57}$ respectively. Reasons for the lack of retention effects in the latter two studies may be the lower training intensity due to the large training groups of 15-20 persons.

\section{Effects on fall frequency and functional fitness}

For the development of fall frequency and functional fitness, planned comparisons did not show any significant contrasts between the simultaneous cognitive-physical and exclusive physical interventions. Nevertheless, global linear time effects indicated that each of the three training programs increased functional fitness and very effectively reduced fall frequency for $\sim 77 \%$ from 0.79 falls per person-year at baseline to 0.18 falls per person-year during the first 6-month period after training. This is about half of the commonly reported minimal fall frequency of 0.33 falls per personyear in this age group. ${ }^{1-3}$ In our study, fall frequency was doubled thereafter to $\sim 0.39$ falls per person-year within the 6-12-month period after training, demonstrating that preventive effects from training were fading out. Our interventions led to a considerably larger reduction in fall frequency compared to the 16 trials included in the meta-analysis by Gillespie et al. ${ }^{10}$ These multicomponent group exercise trials included totally 3,622 participants and showed reduction of fall frequency by $29 \%$ compared to control participants.

Additionally, the present results demonstrated sex-specific training adaptations in favor of the male participants in measures that are related to muscular power performance. We are not aware of any other reports about sex differences in functional outcomes after multicomponent training in elderly persons. Nonetheless, this outcome may be explained by smaller absolute muscle hypertrophic adaptations after strength training in women compared to men, as reported by Melnyk et al. ${ }^{58}$ These authors hypothesized that this difference might be associated with sex differences in blood androgen levels. However, other studies demonstrated similar relative hypertrophic, neuromuscular, or maximal strength adaptations in men and women of younger and older age..$^{59-62}$

\section{Strengths and limitations}

Methodological strengths of this study were the comparably large number of participants and the long training period with follow-up measurements. However, some limitations have to be considered as well. First, the conclusions and recommendations from this study are limited to physically and mentally healthy elderly persons, because such participants were included in the study. Training effects might have been even larger in a population of lower physical and mental status. This assumption is based on the exercise training principle "Initial Values", stating that improvement in the outcome of interest will be greatest in those with lower initial values. ${ }^{34}$ Further, we did not include a passive control group in the design of the study, which means that we could not exactly differentiate between training effects and learning effects from repeated testing. However, this was not the main focus of the present study since previous research has demonstrated training-related gains in physical functioning. ${ }^{10,18,54}$ Based on similar results from the literature and the long intervals of 3 months between test sessions, we assume that performance improvements in our study can mostly be accounted for as training effects. Although participants were blinded to the expected study outcome, blinding of the investigators was not possible since they also supervised and conducted training and testing sessions. This is an additional limitation to this study. 


\section{Conclusion}

This is the first study comparing long-term training and retention effects of two multicomponent cognitive-physical programs with an exclusive physical exercise program on DT gait in healthy older adults. Thereby, a significant advantage of the simultaneous cognitive-physical training programs became evident in DTC of gait variability, which supports our first hypothesis. Nonetheless, each of the three multicomponent programs efficiently increased performance in most other gait variables. In accordance to our second hypothesis, the two novel simultaneous cognitive-physical training programs led to differential training-specific adaptations in the rhythm and variability domains of gait. Gait performance was partly retained over the relatively long period of 1 year after all three programs, with some attenuation in fast walking speed and gait variability. These two variables may serve as early indicators of functional fitness decline and increased fall risk in clinical settings.

To summarize, we conclude that the two novel training concepts of simultaneous cognitive-physical training and the exclusive physical exercise program displayed similarly great potential to counteract age-related decline of physical functioning in the elderly persons, while possible advantages of simultaneous cognitive-physical interventions are well worth further investigation.

\section{Acknowledgments}

This work was supported by the Zürcher Kantonalbank within the framework of sponsoring of Movement Sciences, Sports and Nutritional Sciences at ETH Zurich. Zürcher Kantonalbank had no influence on the study design and the analyses presented in this paper, had no access to the data, and did not contribute to this manuscript in any way. The authors would like to thank PD Dr med Thomas Münzer, chief physician, and the management of Geriatrische Klinik, St Gallen, Switzerland, for supporting the study and providing room for training and data acquisition. Furthermore, we thank our postgraduate students, Marius Angst, Fabienne Hüppin, Manuela Kobelt, Alexandra Schättin, and Sara Tomovic for instructing trainings and helping with data acquisition. We very much appreciated the support of the team of physiotherapists at Geriatrische Klinik, St Gallen. Last but not least, we would like to thank all participants for their enthusiasm, kindness, and patience during our extensive training and testing interventions.

\section{Author contributions}

PE contributed to study preparation and conception, participants' recruitment, data acquisition, statistical analysis, data interpretation, and drafting the manuscript. NT contributed to study conception, conception of serial position training, supporting statistical analysis, data interpretation, and revising manuscript. SH contributed to study preparation, training instruction, data acquisition and interpretation, and revising manuscript. VS contributed to study conception, data interpretation, and revising manuscript. EDB contributed to study conception, data interpretation, and critically revising the manuscript. All authors read and approved the final manuscript.

\section{Disclosure}

The authors report no conflicts of interest in this work.

\section{References}

1. Hausdorff JM, Rios DA, Edelberg HK. Gait variability and fall risk in community-living older adults: a 1-year prospective study. Arch Phys Med Rehabil. 2001;82(8):1050-1056.

2. Gill T, Taylor AW, Pengelly A. A population-based survey of factors relating to the prevalence of falls in older people. Gerontology. 2005; 51(5):340-345.

3. Tinetti ME, Speechley M, Ginter SF. Risk factors for falls among elderly persons living in the community. $N$ Engl J Med. 1988;319(26): 1701-1707.

4. Stel VS, Smit JH, Pluijm SM, Lips P. Consequences of falling in older men and women and risk factors for health service use and functional decline. Age Ageing. 2004;33(1):58-65.

5. Tinetti ME, Kumar C. The patient who falls: "It's always a trade-off". JAMA. 2010;303(3):258-266.

6. Davis JC, Robertson MC, Ashe MC, Liu-Ambrose T, Khan KM, Marra CA. International comparison of cost of falls in older adults living in the community: a systematic review. Osteoporos Int. 2010;21(8): $1295-1306$.

7. Ambrose AF, Paul G, Hausdorff JM. Risk factors for falls among older adults: a review of the literature. Maturitas. 2013;75(1):51-61.

8. Stenhagen M, Ekstrom H, Nordell E, Elmstahl S. Falls in the general elderly population: a 3- and 6-year prospective study of risk factors using data from the longitudinal population study 'Good ageing in Skane'. BMC Geriatr. 2013;13:81.

9. Panel on Prevention of Falls in Older Persons AGS, British Geriatrics Society. Summary of the updated American Geriatrics Society/British Geriatrics Society clinical practice guideline for prevention of falls in older persons. J Am Geriatr Soc. 2011;59(1):148-157.

10. Gillespie LD, Robertson MC, Gillespie WJ, et al. Interventions for preventing falls in older people living in the community. Cochrane Database Syst Rev. 2012;9:CD007146.

11. Campbell AJ, Robertson MC. Rethinking individual and community fall prevention strategies: a meta-regression comparing single and multifactorial interventions. Age Ageing. 2007;36(6):656-662.

12. Sherrington C, Tiedemann A, Fairhall N, Close JC, Lord SR. Exercise to prevent falls in older adults: an updated meta-analysis and best practice recommendations. N S W Public Health Bull. 2011;22(3-4):78-83.

13. Chang JT, Morton SC, Rubenstein LZ, et al. Interventions for the prevention of falls in older adults: systematic review and meta-analysis of randomised clinical trials. BMJ. 2004;328(7441):680.

14. Gardner MM, Robertson MC, Campbell AJ. Exercise in preventing falls and fall related injuries in older people: a review of randomised controlled trials. Br J Sports Med. 2000;34(1):7-17.

15. Muir SW, Gopaul K, Montero Odasso MM. The role of cognitive impairment in fall risk among older adults: a systematic review and meta-analysis. Age Ageing. 2012;41(3):299-308. 
16. Holtzer R, Friedman R, Lipton RB, Katz M, Xue X, Verghese J. The relationship between specific cognitive functions and falls in aging. Neuropsychology. 2007;21(5):540-548.

17. Herman T, Mirelman A, Giladi N, Schweiger A, Hausdorff JM. Executive control deficits as a prodrome to falls in healthy older adults: a prospective study linking thinking, walking, and falling. J Gerontol A Biol Sci Med Sci. 2010;65(10):1086-1092.

18. van het Reve E, de Bruin ED. Strength-balance supplemented with computerized cognitive training to improve dual task gait and divided attention in older adults: a multicenter randomized-controlled trial. BMC Geriatr. 2014;14:134.

19. Theill N, Schumacher V, Adelsberger R, Martin M, Jancke L. Effects of simultaneously performed cognitive and physical training in older adults. BMC Neurosci. 2013;14:103.

20. Pichierri G, Murer K, de Bruin ED. A cognitive-motor intervention using a dance video game to enhance foot placement accuracy and gait under dual task conditions in older adults: a randomized controlled trial. BMC Geriatr. 2012;12:74

21. de Bruin ED, Reith A, Dörflinger M, Murer K. Feasibility of strengthbalance training extended with computer game dancing in older people; does it affect dual task costs of walking? J Nov Physiother. 2011; $1: 104$.

22. Forte R, Boreham CA, Leite JC, et al. Enhancing cognitive functioning in the elderly: multicomponent vs resistance training. Clin Interv Aging. 2013;8:19-27.

23. Eggenberger P, Schumacher V, Angst M, Theill N, de Bruin ED. Does multicomponent physical exercise with simultaneous cognitive training boost cognitive performance in older adults? A 6-month randomized controlled trial with a 1-year follow-up. Clin Interv Aging. 2015;10:1335-1349.

24. Moher D, Hopewell S, Schulz KF, et al. CONSORT 2010 explanation and elaboration: updated guidelines for reporting parallel group randomised trials. BMJ. 2010;340:c869.

25. Pro Senectute St. Gallen [homepage on the Internet]. Available from: http://www.sg.pro-senectute.ch. Accessed July 18, 2015.

26. Geriatrische Klinik St Gallen [homepage on the Internet]. Available from: http://www.gesundheitundalter.ch/Home/GeriatrischeKlinik/ Portrait/tabid/106/Default.aspx. Accessed August 8, 2012.

27. Amt für Sport Kanton St Gallen [homepage on the Internet]. Available from: http://www.sg.ch/home/bildung/sport/Erwachsene.html. Accessed August 8, 2012.

28. MacKenzie DM, Copp P, Shaw RJ, Goodwin GM. Brief cognitive screening of the elderly: a comparison of the Mini-Mental State Examination (MMSE), Abbreviated Mental Test (AMT) and Mental Status Questionnaire (MSQ). Psychol Med. 1996;26(2):427-430.

29. Folstein MF, Folstein SE, McHugh PR. "Mini-mental state". A practical method for grading the cognitive state of patients for the clinician. J Psychiatr Res. 1975;12(3):189-198.

30. Faul F, Erdfelder E, Lang AG, Buchner A. G*Power 3: a flexible statistical power analysis program for the social, behavioral, and biomedical sciences. Behav Res Methods. 2007;39(2):175-191.

31. Randomization.com [homepage on the Internet]. Available from: http:// randomization.com. Accessed September 21, 2012.

32. American College of Sports Medicine; Chodzko-Zajko WJ, Proctor DN, et al. American College of Sports Medicine position stand. Exercise and physical activity for older adults. Med Sci Sports Exerc. 2009;41(7):1510-1530.

33. Granacher U, Muehlbauer T, Gruber M. A qualitative review of balance and strength performance in healthy older adults: impact for testing and training. J Aging Res. 2012;2012:708905.

34. Ammann BC, Knols RH, Baschung P, de Bie RA, de Bruin ED. Application of principles of exercise training in sub-acute and chronic stroke survivors: a systematic review. BMC Neurol. 2014;14:167.

35. StepMania.com [homepage on the Internet]. Available from: http:// www.stepmania.com. Accessed September 9, 2012.

36. de Bruin ED, Murer K. Effect of additional functional exercises on balance in elderly people. Clin Rehabil. 2007;21(2):112-121.
37. Webster KE, Wittwer JE, Feller JA. Validity of the GAITRite walkway system for the measurement of averaged and individual step parameters of gait. Gait Posture. 2005;22(4):317-321.

38. van Uden CJ, Besser MP. Test-retest reliability of temporal and spatial gait characteristics measured with an instrumented walkway system (GAITRite). BMC Musculoskelet Disord. 2004;5:13.

39. Bilney B, Morris M, Webster K. Concurrent related validity of the GAITRite walkway system for quantification of the spatial and temporal parameters of gait. Gait Posture. 2003;17(1):68-74

40. Al-Yahya E, Dawes H, Smith L, Dennis A, Howells K, Cockburn J. Cognitive motor interference while walking: a systematic review and meta-analysis. Neurosci Biobehav Rev. 2011;35(3):715-728.

41. Guralnik JM, Simonsick EM, Ferrucci L, et al. A short physical performance battery assessing lower extremity function: association with self-reported disability and prediction of mortality and nursing home admission. J Gerontol. 1994;49(2):M85-M94.

42. Guralnik JM. Assessing Physical Performance in the Older Patient; 2013; Available from: http://www.grc.nia.nih.gov/branches/leps/sppb/. Accessed 2 April, 2015.

43. Laboratories ATSCoPSfCPF. ATS statement: guidelines for the sixminute walk test. Am J Respir Crit Care Med. 2002;166(1):111-117.

44. Neely G, Ljunggren G, Sylven C, Borg G. Comparison between the Visual Analogue Scale (VAS) and the Category Ratio Scale (CR-10) for the evaluation of leg exertion. Int J Sports Med. 1992;13(2): 133-136.

45. Yardley L, Beyer N, Hauer K, Kempen G, Piot-Ziegler C, Todd C. Development and initial validation of the Falls Efficacy Scale-International (FES-I). Age Ageing. 2005;34(6):614-619.

46. Gauggel S, Birkner B. Validität und Reliabilität einer deutschen Version der Geriatrischen Depressionsskala (GDS). [Validity and reliability of a German version of the Geriatric Depression Scale (GDS)]. Zeitschrift für Klinische Psychologie. 1999;28(1):18-27.

47. Cohen J. Statistical Power Analysis for the Behavioral Sciences. 2nd ed. Hillsdale, NJ: Lawrence Erlbaum; 1988.

48. Lord S, Galna B, Verghese J, Coleman S, Burn D, Rochester L. Independent domains of gait in older adults and associated motor and nonmotor attributes: validation of a factor analysis approach. J Gerontol A Biol Sci Med Sci. 2013;68(7):820-827.

49. Verlinden VJ, van der Geest JN, Hofman A, Ikram MA. Cognition and gait show a distinct pattern of association in the general population. Alzheimers Dement. 2014;10(3):328-335.

50. Herman T, Giladi N, Gruendlinger L, Hausdorff JM. Six weeks of intensive treadmill training improves gait and quality of life in patients with Parkinson's disease: a pilot study. Arch Phys Med Rehabil. 2007;88(9):1154-1158.

51. Zimmerman ME, Lipton RB, Pan JW, Hetherington HP, Verghese J. MRI- and MRS-derived hippocampal correlates of quantitative locomotor function in older adults. Brain Res. 2009;1291:73-81.

52. Wicking M, Nees F, Steiger F. Neuropsychological measures of hippocampal function. Front Neurol Neurosci. 2014;34:60-70.

53. Zimmerman ME, Pan JW, Hetherington HP, et al. Hippocampal neurochemistry, neuromorphometry, and verbal memory in nondemented older adults. Neurology. 2008;70(18):1594-1600.

54. Gudlaugsson J, Gudnason V, Aspelund T, et al. Effects of a 6-month multimodal training intervention on retention of functional fitness in older adults: a randomized-controlled cross-over design. Int J Behav Nutr Phys Act. 2012;9:107.

55. Toraman NF, Ayceman N. Effects of six weeks of detraining on retention of functional fitness of old people after nine weeks of multicomponent training. Br J Sports Med. 2005;39(8):565-568. [discussion 568].

56. Seco J, Abecia LC, Echevarría E, et al. A long-term physical activity training program increases strength and flexibility, and improves balance in older adults. Rehabil Nurs. 2013;38(1):37-47.

57. Carvalho MJ, Marques E, Mota J. Training and detraining effects on functional fitness after a multicomponent training in older women. Gerontology. 2009;55(1):41-48. 
58. Melnyk JA, Rogers MA, Hurley BF. Effects of strength training and detraining on regional muscle in young and older men and women. Eur J Appl Physiol. 2009;105(6):929-938.

59. Folland JP, Williams AG. The adaptations to strength training: morphological and neurological contributions to increased strength. Sports Med. 2007;37(2):145-168.

60. Roth SM, Ivey FM, Martel GF, et al. Muscle size responses to strength training in young and older men and women. J Am Geriatr Soc. 2001; 49(11):1428-1433.

61. Ivey FM, Tracy BL, Lemmer JT, et al. Effects of strength training and detraining on muscle quality: age and gender comparisons. J Gerontol A Biol Sci Med Sci. 2000;55(3):B152-B157. [discussion B158-B159].
62. Tracy BL, Ivey FM, Hurlbut D, et al. Muscle quality. II. Effects Of strength training in 65- to 75-yr-old men and women. J Appl Physiol (1985). 1999;86(1):195-201.

63. Nelson ME, Rejeski WJ, Blair SN, et al. Physical activity and public health in older adults: recommendation from the American College of Sports Medicine and the American Heart Association. Med Sci Sports Exerc. 2007;39(8):1435-1445. 


\section{Supplementary materials}

Table SI Multiple regression for the linear global time effect (from pretest to 6-month test, $\mathrm{N}=7 \mathrm{I}$ ) and the interaction between orthogonal contrasts and time effect for gait variable "velocity"

\begin{tabular}{|c|c|c|c|c|c|c|c|c|}
\hline \multirow{2}{*}{$\begin{array}{l}\text { Dependent variable } \\
\text { Velocity preferred }\end{array}$} & \multirow{2}{*}{$\begin{array}{l}\text { Predictor } \\
\text { Linear global time effect }\end{array}$} & \multirow{2}{*}{$\begin{array}{l}b \\
7.10\end{array}$} & \multicolumn{2}{|l|}{$95 \% \mathrm{Cl}$} & \multirow{2}{*}{$\begin{array}{l}S E b \\
0.97\end{array}$} & \multirow{2}{*}{$\begin{array}{l}\beta \\
0.23\end{array}$} & \multirow{2}{*}{$\begin{array}{l}P \text { two tailed } \\
<0.00 \text { I }^{* * *}\end{array}$} & \multirow{2}{*}{$\begin{array}{l}R^{2} \text {-change } \\
0.053\end{array}$} \\
\hline & & & 5.19 & 9.01 & & & & \\
\hline & Quadratic global time effect & -1.03 & -2.13 & 0.08 & 0.56 & -0.06 & $0.068^{t}$ & 0.003 \\
\hline & Linear interaction $A B \times C$ & -0.26 & -1.60 & 1.07 & 0.67 & -0.01 & 0.695 & 0.000 \\
\hline & Linear interaction $\mathrm{A} \times \mathrm{B}$ & -1.63 & -4.00 & 0.75 & 1.20 & -0.04 & 0.178 & 0.002 \\
\hline \multirow[t]{4}{*}{ Velocity fast } & Linear global time effect & 8.64 & 6.35 & 10.92 & 1.16 & 0.22 & $<0.001 * * *$ & 0.048 \\
\hline & Quadratic global time effect & -0.86 & -2.18 & 0.47 & 0.67 & -0.04 & 0.203 & 0.001 \\
\hline & Linear interaction $A B \times C$ & -0.08 & -1.68 & 1.51 & 0.81 & 0.00 & 0.919 & 0.000 \\
\hline & Linear interaction $\mathrm{A} \times \mathrm{B}$ & 2.27 & -0.57 & 5.11 & 1.44 & 0.05 & 0.116 & 0.002 \\
\hline \multirow[t]{4}{*}{ Velocity preferred DT } & Linear global time effect & 6.79 & 4.60 & 8.99 & 1.11 & 0.18 & $<0.00 I^{* * * *}$ & 0.033 \\
\hline & Quadratic global time effect & -0.48 & -1.74 & 0.79 & 0.64 & -0.02 & 0.456 & 0.000 \\
\hline & Linear interaction $A B \times C$ & -0.33 & -1.85 & 1.20 & 0.77 & -0.01 & 0.674 & 0.000 \\
\hline & Linear interaction $\mathrm{A} \times \mathrm{B}$ & -1.00 & -3.72 & 1.72 & 1.38 & -0.02 & 0.468 & 0.000 \\
\hline \multirow[t]{4}{*}{ Velocity fast DT } & Linear global time effect & 7.90 & 5.40 & 10.39 & 1.26 & 0.20 & $<0.001 * * *$ & 0.039 \\
\hline & Quadratic global time effect & 0.67 & -0.77 & 2.11 & 0.73 & 0.03 & 0.361 & 0.001 \\
\hline & Linear interaction $A B \times C$ & -0.69 & -2.43 & 1.05 & 0.88 & -0.03 & 0.431 & 0.001 \\
\hline & Linear interaction $\mathrm{A} \times \mathrm{B}$ & -0.03 & -3.13 & 3.07 & 1.57 & 0.00 & 0.985 & 0.000 \\
\hline \multirow[t]{4}{*}{ Velocity preferred DTC } & Linear global time effect & 0.00 & -0.02 & 0.02 & 0.01 & 0.00 & 0.930 & 0.000 \\
\hline & Quadratic global time effect & 0.00 & -0.01 & 0.01 & 0.01 & 0.03 & 0.480 & 0.001 \\
\hline & Linear interaction $A B \times C$ & 0.00 & -0.01 & 0.01 & 0.01 & -0.01 & 0.858 & 0.000 \\
\hline & Linear interaction $A \times B$ & 0.00 & -0.02 & 0.03 & 0.01 & 0.02 & 0.717 & 0.000 \\
\hline \multirow[t]{4}{*}{ Velocity fast DTC } & Linear global time effect & 0.01 & -0.01 & 0.02 & 0.01 & 0.04 & 0.461 & 0.002 \\
\hline & Quadratic global time effect & 0.01 & 0.00 & 0.02 & 0.01 & 0.10 & $0.065^{t}$ & 0.011 \\
\hline & Linear interaction $A B \times C$ & -0.01 & -0.02 & 0.01 & 0.01 & -0.06 & 0.258 & 0.004 \\
\hline & Linear interaction $A \times B$ & -0.01 & -0.04 & 0.01 & 0.01 & -0.07 & 0.213 & 0.005 \\
\hline
\end{tabular}

Notes: Bold values indicate significance or trend. $* * * P<0.001$. $P<0.10$ trend.

Abbreviations: A, DANCE; B, MEMORY; C, PHYS; Cl, confidence interval; DANCE, virtual reality video game dancing; DT, dual-task; DTC, dual-task cost; MEMORY, treadmill walking with simultaneous verbal memory training; PHYS, treadmill walking; SE, \pm standard error.

Table S2 Multiple regression for the linear global time effect (from pretest to 6-month test, $N=7 \mathrm{I}$ ) and the interaction between orthogonal contrasts and time effect for gait variable "step length"

\begin{tabular}{|c|c|c|c|c|c|c|c|c|}
\hline Dependent variable & Predictor & $b$ & $95 \% \mathrm{Cl}$ & & $S E b$ & $\beta$ & $P$ two tailed & $R^{2}$-change \\
\hline \multirow[t]{4}{*}{ Step length preferred } & Linear global time effect & 1.71 & 1.12 & 2.30 & 0.30 & 0.15 & $<0.00 I^{* * * *}$ & 0.022 \\
\hline & Quadratic global time effect & -0.31 & -0.65 & 0.03 & 0.17 & -0.05 & $0.072^{\mathrm{t}}$ & 0.002 \\
\hline & Linear interaction $A B \times C$ & -0.12 & -0.54 & 0.29 & 0.21 & -0.02 & 0.551 & 0.000 \\
\hline & Linear interaction $A \times B$ & -0.54 & -1.27 & 0.19 & 0.37 & -0.04 & 0.147 & 0.001 \\
\hline \multirow[t]{4}{*}{ Step length fast } & Linear global time effect & 1.55 & 0.97 & 2.13 & 0.30 & 0.11 & $<0.00 I^{* * *}$ & 0.012 \\
\hline & Quadratic global time effect & -0.16 & -0.50 & 0.18 & 0.17 & -0.02 & 0.352 & 0.000 \\
\hline & Linear interaction $A B \times C$ & -0.19 & -0.60 & 0.21 & 0.21 & -0.02 & 0.346 & 0.000 \\
\hline & Linear interaction $\mathrm{A} \times \mathrm{B}$ & -0.19 & -0.92 & 0.53 & 0.37 & -0.01 & 0.600 & 0.000 \\
\hline \multirow[t]{4}{*}{ Step length preferred DT } & Linear global time effect & 1.98 & 1.37 & 2.60 & 0.31 & 0.15 & $<0.00 I^{* * * *}$ & 0.024 \\
\hline & Quadratic global time effect & -0.02 & -0.37 & 0.34 & 0.18 & 0.00 & 0.920 & 0.000 \\
\hline & Linear interaction $A B \times C$ & -0.34 & -0.77 & 0.09 & 0.22 & -0.04 & 0.119 & 0.001 \\
\hline & Linear interaction $A \times B$ & -0.49 & -1.25 & 0.28 & 0.39 & -0.03 & 0.209 & 0.001 \\
\hline \multirow[t]{2}{*}{ Step length fast DT } & Linear global time effect & 1.69 & 1.06 & 2.33 & 0.32 & 0.13 & $<0.00 I^{* * * *}$ & 0.016 \\
\hline & Quadratic global time effect & 0.16 & -0.21 & 0.52 & 0.19 & 0.02 & 0.400 & 0.000 \\
\hline
\end{tabular}


Table S2 (Continued)

\begin{tabular}{|c|c|c|c|c|c|c|c|c|}
\hline Dependent variable & Predictor & $b$ & $95 \% \mathrm{Cl}$ & & SE $b$ & $\beta$ & $P$ two tailed & $R^{2}$-change \\
\hline & Linear interaction $A B \times C$ & -0.33 & -0.78 & 0.11 & 0.22 & -0.04 & 0.136 & 0.001 \\
\hline & Linear interaction $\mathrm{A} \times \mathrm{B}$ & -0.03 & -0.81 & 0.76 & 0.40 & 0.00 & 0.947 & 0.000 \\
\hline \multirow[t]{4}{*}{ Step length preferred DTC } & Linear global time effect & 0.00 & -0.01 & 0.01 & 0.01 & 0.04 & 0.482 & 0.001 \\
\hline & Quadratic global time effect & 0.00 & 0.00 & 0.01 & 0.00 & 0.08 & 0.127 & 0.006 \\
\hline & Linear interaction $A B \times C$ & 0.00 & -0.01 & 0.00 & 0.00 & -0.06 & 0.293 & 0.003 \\
\hline & Linear interaction $A \times B$ & 0.00 & -0.01 & 0.01 & 0.01 & -0.01 & 0.858 & 0.000 \\
\hline \multirow[t]{4}{*}{ Step length fast DTC } & Linear global time effect & 0.00 & -0.01 & 0.01 & 0.00 & 0.03 & 0.494 & 0.001 \\
\hline & Quadratic global time effect & 0.01 & 0.00 & 0.01 & 0.00 & 0.09 & $0.049 *$ & 0.009 \\
\hline & Linear interaction $A B \times C$ & 0.00 & -0.01 & 0.00 & 0.00 & -0.05 & 0.264 & 0.003 \\
\hline & Linear interaction $\mathrm{A} \times \mathrm{B}$ & 0.00 & -0.01 & 0.01 & 0.01 & 0.00 & 0.983 & 0.000 \\
\hline
\end{tabular}

Notes: Bold values indicate significance or trend. $* P<0.05$. $* * * P<0.001$. ${ }^{t} P<0.10$ trend.

Abbreviations: A, DANCE; B, MEMORY; C, PHYS; Cl, confidence interval; DANCE, virtual reality video game dancing; DT, dual-task; DTC, dual-task cost; MEMORY, treadmill walking with simultaneous verbal memory training; PHYS, treadmill walking; SE, \pm standard error.

Table S3 Multiple regression for the linear global time effect (from pretest to 6-month test, $\mathrm{N}=7 \mathrm{I}$ ) and the interaction between orthogonal contrasts and time effect for gait variable "step length variability"

\begin{tabular}{|c|c|c|c|c|c|c|c|c|}
\hline \multirow{2}{*}{$\begin{array}{l}\text { Dependent variable } \\
\text { Step length variability preferred }\end{array}$} & \multirow{2}{*}{$\begin{array}{l}\text { Predictor } \\
\text { Linear global time effect }\end{array}$} & \multirow{2}{*}{$\frac{b}{-0.39}$} & \multicolumn{2}{|c|}{$95 \% \mathrm{Cl}$} & \multirow{2}{*}{$\begin{array}{l}S E b \\
0.06\end{array}$} & \multirow{2}{*}{$\frac{\beta}{-0.35}$} & \multirow{2}{*}{$\begin{array}{l}\text { P two tailed } \\
<0.00 \text { I }^{* * *}\end{array}$} & \multirow{2}{*}{$\begin{array}{l}R^{2} \text {-change } \\
0.118\end{array}$} \\
\hline & & & -0.50 & -0.27 & & & & \\
\hline & Quadratic global time effect & 0.08 & 0.01 & 0.15 & 0.03 & 0.12 & $0.020 *$ & 0.015 \\
\hline & Linear interaction $A B \times C$ & -0.03 & -0.11 & 0.06 & 0.04 & -0.03 & 0.548 & 0.001 \\
\hline & Linear interaction $\mathrm{A} \times \mathrm{B}$ & 0.01 & -0.13 & 0.16 & 0.07 & 0.01 & 0.866 & 0.000 \\
\hline \multirow[t]{4}{*}{ Step length variability fast } & Linear global time effect & -0.15 & -0.31 & 0.01 & 0.08 & -0.11 & $0.059^{t}$ & 0.013 \\
\hline & Quadratic global time effect & 0.13 & 0.04 & 0.22 & 0.05 & 0.17 & $0.005 * *$ & 0.029 \\
\hline & Linear interaction $A B \times C$ & -0.05 & -0.16 & 0.06 & 0.06 & -0.05 & 0.377 & 0.003 \\
\hline & Linear interaction $A \times B$ & 0.01 & -0.18 & 0.21 & 0.10 & 0.01 & 0.911 & 0.000 \\
\hline \multirow[t]{4}{*}{ Step length variability preferred DT } & Linear global time effect & -0.32 & -0.50 & -0.13 & 0.09 & -0.18 & $0.001 * *$ & 0.030 \\
\hline & Quadratic global time effect & 0.03 & -0.07 & 0.14 & 0.05 & 0.03 & 0.549 & 0.001 \\
\hline & Linear interaction $A B \times C$ & -0.02 & -0.14 & 0.11 & 0.07 & -0.01 & 0.817 & 0.000 \\
\hline & Linear interaction $A \times B$ & 0.22 & -0.01 & 0.45 & 0.12 & 0.10 & $0.062^{\mathrm{t}}$ & 0.009 \\
\hline \multirow[t]{4}{*}{ Step length variability fast DT } & Linear global time effect & -0.10 & -0.30 & 0.09 & 0.10 & -0.06 & 0.286 & 0.004 \\
\hline & Quadratic global time effect & 0.07 & -0.04 & 0.19 & 0.06 & 0.07 & 0.192 & 0.005 \\
\hline & Linear interaction $A B \times C$ & 0.05 & -0.09 & 0.18 & 0.07 & 0.04 & 0.490 & 0.002 \\
\hline & Linear interaction $A \times B$ & 0.14 & -0.10 & 0.38 & 0.12 & 0.06 & 0.262 & 0.004 \\
\hline \multirow[t]{4}{*}{ Step length variability preferred DTC } & Linear global time effect & 0.07 & -0.04 & 0.17 & 0.05 & 0.08 & 0.229 & 0.006 \\
\hline & Quadratic global time effect & -0.01 & -0.07 & 0.05 & 0.03 & -0.02 & $0.8 \mathrm{II}$ & 0.000 \\
\hline & Linear interaction $A B \times C$ & -0.02 & -0.09 & 0.06 & 0.04 & -0.03 & 0.693 & 0.001 \\
\hline & Linear interaction $\mathrm{A} \times \mathrm{B}$ & 0.10 & -0.04 & 0.23 & 0.07 & 0.09 & 0.150 & 0.008 \\
\hline \multirow[t]{4}{*}{ Step length variability fast DTC } & Linear global time effect & 0.00 & -0.11 & 0.12 & 0.06 & 0.00 & 0.962 & 0.000 \\
\hline & Quadratic global time effect & -0.05 & -0.11 & 0.02 & 0.03 & -0.10 & 0.141 & 0.010 \\
\hline & Linear interaction $A B \times C$ & 0.04 & -0.04 & 0.11 & 0.04 & 0.06 & 0.375 & 0.004 \\
\hline & Linear interaction $\mathrm{A} \times \mathrm{B}$ & 0.05 & -0.09 & 0.19 & 0.07 & 0.05 & 0.468 & 0.002 \\
\hline
\end{tabular}

Notes: Bold values indicate significance or trend. $* P<0.05$. $* * P<0.01$. $* * * P<0.001$. ${ }^{t} P<0.10$ trend.

Abbreviations: A, DANCE; B, MEMORY; C, PHYS; Cl, confidence interval; DANCE, virtual reality video game dancing; DT, dual-task; DTC, dual-task cost; MEMORY, treadmill walking with simultaneous verbal memory training; PHYS, treadmill walking; SE, \pm standard error.

Table S4 Multiple regression for the linear global time effect (from pretest to 6-month test, $\mathrm{N}=7 \mathrm{I}$ ) and the interaction between orthogonal contrasts and time effect for gait variable "step time"

\begin{tabular}{|c|c|c|c|c|c|c|c|c|}
\hline Dependent variable & Predictor & $b$ & $95 \% \mathrm{Cl}$ & & $S E b$ & $\beta$ & $P$ two tailed & $R^{2}$-change \\
\hline \multirow[t]{4}{*}{ Step time preferred } & Linear global time effect & -0.02 & -0.024 & -0.011 & 0.00 & -0.21 & $<0.001 * * *$ & 0.043 \\
\hline & Quadratic global time effect & 0.00 & -0.002 & 0.005 & 0.00 & 0.03 & 0.452 & 0.001 \\
\hline & Linear interaction $A B \times C$ & 0.00 & -0.002 & 0.007 & 0.00 & 0.04 & 0.331 & 0.001 \\
\hline & Linear interaction $A \times B$ & 0.00 & -0.004 & 0.012 & 0.00 & 0.03 & 0.373 & 0.001 \\
\hline \multirow[t]{4}{*}{ Step time fast } & Linear global time effect & -0.01 & -0.017 & -0.009 & 0.00 & -0.23 & $<0.001 * * *$ & 0.054 \\
\hline & Quadratic global time effect & 0.00 & -0.001 & 0.003 & 0.00 & 0.04 & 0.264 & 0.001 \\
\hline & Linear interaction $A B \times C$ & 0.00 & -0.003 & 0.002 & 0.00 & -0.01 & 0.735 & 0.000 \\
\hline & Linear interaction $\mathrm{A} \times \mathrm{B}$ & -0.01 & -0.011 & -0.002 & 0.00 & -0.09 & $0.007^{* *} *$ & 0.009 \\
\hline
\end{tabular}


Table S4 (Continued)

\begin{tabular}{|c|c|c|c|c|c|c|c|c|}
\hline Dependent variable & Predictor & $b$ & $95 \% \mathrm{Cl}$ & & $S E b$ & $\beta$ & $P$ two tailed & $R^{2}$-change \\
\hline \multirow[t]{4}{*}{ Step time preferred DT } & Linear global time effect & -0.02 & -0.027 & -0.005 & 0.01 & -0.10 & $0.006 * *$ & $0.01 \mathrm{I}$ \\
\hline & Quadratic global time effect & 0.00 & -0.003 & 0.010 & 0.00 & 0.04 & 0.323 & 0.001 \\
\hline & Linear interaction $A B \times C$ & 0.00 & -0.006 & 0.009 & 0.00 & 0.02 & 0.680 & 0.000 \\
\hline & Linear interaction $\mathrm{A} \times \mathrm{B}$ & 0.01 & -0.003 & 0.024 & 0.01 & 0.06 & 0.136 & 0.003 \\
\hline \multirow[t]{4}{*}{ Step time fast DT } & Linear global time effect & -0.02 & -0.022 & -0.008 & 0.00 & -0.16 & $<0.001 * * *$ & 0.026 \\
\hline & Quadratic global time effect & 0.00 & -0.005 & 0.003 & 0.00 & -0.02 & 0.662 & 0.000 \\
\hline & Linear interaction $A B \times C$ & 0.00 & -0.004 & 0.005 & 0.00 & 0.01 & 0.898 & 0.000 \\
\hline & Linear interaction $\mathrm{A} \times \mathrm{B}$ & 0.00 & -0.008 & 0.008 & 0.00 & 0.00 & 0.993 & 0.000 \\
\hline \multirow[t]{4}{*}{ Step time preferred DTC } & Linear global time effect & 0.00 & -0.016 & 0.024 & 0.01 & 0.02 & 0.690 & 0.000 \\
\hline & Quadratic global time effect & 0.00 & -0.009 & 0.014 & 0.01 & 0.02 & 0.667 & 0.000 \\
\hline & Linear interaction $A B \times C$ & 0.00 & -0.016 & 0.012 & 0.01 & -0.01 & 0.808 & 0.000 \\
\hline & Linear interaction $A \times B$ & 0.01 & -0.012 & 0.038 & 0.01 & 0.05 & 0.295 & 0.002 \\
\hline \multirow[t]{4}{*}{ Step time fast DTC } & Linear global time effect & 0.00 & -0.015 & 0.017 & 0.01 & 0.01 & 0.901 & 0.000 \\
\hline & Quadratic global time effect & -0.01 & -0.014 & 0.004 & 0.01 & -0.05 & 0.287 & 0.002 \\
\hline & Linear interaction $A B \times C$ & 0.00 & -0.009 & 0.013 & 0.01 & 0.02 & 0.726 & 0.000 \\
\hline & Linear interaction $\mathrm{A} \times \mathrm{B}$ & 0.02 & -0.001 & 0.038 & 0.01 & 0.08 & $0.069^{t}$ & 0.006 \\
\hline
\end{tabular}

Notes: Bold values indicate significance or trend. $* * P<0.01$. $* * * P<0.001$. ${ }^{t} P<0.10$ trend.

Abbreviations: A, DANCE; B, MEMORY; C, PHYS; Cl, confidence interval; DANCE, virtual reality video game dancing; DT, dual-task; DTC, dual-task cost; MEMORY, treadmill walking with simultaneous verbal memory training; PHYS, treadmill walking; SE, \pm standard error.

Table S5 Multiple regression for the linear global time effect (from pretest to 6-month test, $\mathrm{N}=7 \mathrm{I}$ ) and the interaction between orthogonal contrasts and time effect for gait variable "step time variability"

\begin{tabular}{|c|c|c|c|c|c|c|c|c|}
\hline Dependent variable & Predictor & $b$ & $95 \% \mathrm{Cl}$ & & $S E b$ & $\beta$ & $P$ two tailed & $\overline{R^{2} \text {-change }}$ \\
\hline \multirow[t]{4}{*}{ Step time variability preferred } & Linear global time effect & -0.004 & -0.005 & -0.003 & 0.001 & -0.28 & $<0.00 I^{* * * *}$ & 0.081 \\
\hline & Quadratic global time effect & 0.000 & 0.000 & 0.001 & 0.000 & 0.05 & 0.318 & 0.003 \\
\hline & Linear interaction $A B \times C$ & 0.001 & 0.000 & 0.002 & 0.000 & 0.11 & $0.034^{*}$ & 0.012 \\
\hline & Linear interaction $\mathrm{A} \times \mathrm{B}$ & -0.001 & -0.003 & 0.001 & 0.001 & -0.05 & 0.301 & 0.003 \\
\hline \multirow[t]{4}{*}{ Step time variability fast } & Linear global time effect & -0.006 & -0.009 & -0.004 & 0.001 & -0.31 & $<0.00 I^{* * * *}$ & 0.098 \\
\hline & Quadratic global time effect & 0.001 & 0.000 & 0.003 & 0.001 & 0.12 & $0.067^{t}$ & 0.014 \\
\hline & Linear interaction $A B \times C$ & 0.000 & -0.002 & 0.002 & 0.001 & 0.02 & 0.791 & 0.000 \\
\hline & Linear interaction $A \times B$ & -0.002 & -0.005 & 0.001 & 0.002 & -0.08 & 0.204 & 0.007 \\
\hline \multirow[t]{4}{*}{ Step time variability preferred DT } & Linear global time effect & -0.003 & -0.007 & 0.000 & 0.002 & -0.09 & $0.047 *$ & 0.008 \\
\hline & Quadratic global time effect & 0.000 & -0.001 & 0.002 & 0.001 & 0.02 & 0.631 & 0.000 \\
\hline & Linear interaction $A B \times C$ & 0.000 & -0.002 & 0.002 & 0.001 & 0.00 & 0.949 & 0.000 \\
\hline & Linear interaction $\mathrm{A} \times \mathrm{B}$ & 0.003 & -0.001 & 0.007 & 0.002 & 0.06 & 0.165 & 0.004 \\
\hline \multirow[t]{4}{*}{ Step time variability fast DT } & Linear global time effect & -0.004 & -0.007 & 0.000 & 0.002 & -0.12 & $0.024 *$ & 0.015 \\
\hline & Quadratic global time effect & -0.002 & -0.004 & 0.000 & 0.001 & -0.11 & $0.047 *$ & 0.011 \\
\hline & Linear interaction $A B \times C$ & -0.001 & -0.003 & 0.001 & 0.001 & -0.04 & 0.438 & 0.002 \\
\hline & Linear interaction $\mathrm{A} \times \mathrm{B}$ & 0.002 & -0.002 & 0.006 & 0.002 & 0.05 & 0.339 & 0.003 \\
\hline \multirow[t]{4}{*}{ Step time variability preferred DTC } & Linear global time effect & 0.194 & -0.015 & 0.402 & 0.106 & 0.10 & $0.069^{t}$ & 0.010 \\
\hline & Quadratic global time effect & -0.027 & -0.148 & 0.093 & 0.061 & -0.03 & 0.657 & 0.001 \\
\hline & Linear interaction $A B \times C$ & -0.071 & -0.216 & 0.075 & 0.074 & -0.05 & 0.339 & 0.003 \\
\hline & Linear interaction $\mathrm{A} \times \mathrm{B}$ & 0.247 & -0.012 & 0.506 & 0.131 & 0.11 & $0.062^{\mathrm{t}}$ & 0.011 \\
\hline \multirow[t]{4}{*}{ Step time variability fast DTC } & Linear global time effect & 0.123 & -0.083 & 0.329 & 0.104 & 0.07 & 0.241 & 0.005 \\
\hline & Quadratic global time effect & -0.131 & -0.250 & -0.012 & 0.060 & -0.13 & $0.032 *$ & 0.016 \\
\hline & Linear interaction $A B \times C$ & -0.125 & -0.268 & 0.019 & 0.073 & -0.10 & $0.088^{t}$ & 0.010 \\
\hline & Linear interaction $\mathrm{A} \times \mathrm{B}$ & 0.181 & -0.075 & 0.437 & 0.129 & 0.08 & 0.165 & 0.007 \\
\hline
\end{tabular}

Notes: Bold values indicate significance or trend. $* P<0.05$. $* * * P<0.001$. ${ }^{\mathrm{t}} \mathrm{P}<0.10$ trend.

Abbreviations: A, DANCE; B, MEMORY; C, PHYS; CI, confidence interval; DANCE, virtual reality video game dancing; DT, dual-task; DTC, dual-task cost; MEMORY, treadmill walking with simultaneous verbal memory training; PHYS, treadmill walking; SE, \pm standard error. 
Table S6 Repeated-measures ANOVA from 6 months to follow-up test for gait variables, N=47

\begin{tabular}{|c|c|c|c|c|}
\hline Dependent variable & Effect & $F(2,44)$ & $P$ two tailed & $r$ \\
\hline \multirow[t]{2}{*}{ Velocity preferred } & Time & 0.090 & 0.765 & 0.05 \\
\hline & Time $\times$ intervention & 0.207 & 0.813 & 0.07 \\
\hline \multirow[t]{2}{*}{ Velocity fast } & Time & 7.844 & $0.008 * *$ & 0.39 \\
\hline & Time $\times$ intervention & 2.097 & 0.135 & 0.21 \\
\hline \multirow[t]{2}{*}{ Velocity preferred DT } & Time & 7.095 & $0.011 *$ & 0.37 \\
\hline & Time $\times$ intervention & 0.094 & 0.910 & 0.05 \\
\hline \multirow[t]{2}{*}{ Velocity fast DT } & Time & 0.073 & 0.789 & 0.04 \\
\hline & Time $\times$ intervention & 0.299 & 0.743 & 0.08 \\
\hline \multirow[t]{2}{*}{ Velocity preferred DTC } & Time & 11.667 & $0.00 I^{* * *}$ & 0.46 \\
\hline & Time $\times$ intervention & 0.075 & 0.928 & 0.04 \\
\hline \multirow[t]{2}{*}{ Velocity fast DTC } & Time & 9.498 & $0.004^{* *}$ & 0.42 \\
\hline & Time $\times$ intervention & 1.718 & 0.191 & 0.19 \\
\hline \multirow[t]{2}{*}{ Step length preferred } & Time & 0.004 & 0.951 & 0.01 \\
\hline & Time $\times$ intervention & 0.179 & 0.837 & 0.06 \\
\hline \multirow[t]{2}{*}{ Step length fast } & Time & 10.23 & $0.003 * *$ & 0.43 \\
\hline & Time $\times$ intervention & 0.444 & 0.644 & 0.10 \\
\hline \multirow[t]{2}{*}{ Step length preferred DT } & Time & 2.413 & 0.127 & 0.23 \\
\hline & Time $\times$ intervention & 0.392 & 0.678 & 0.09 \\
\hline \multirow[t]{2}{*}{ Step length fast DT } & Time & 0.04 & 0.842 & 0.03 \\
\hline & Time $\times$ intervention & 0.552 & 0.580 & 0.11 \\
\hline \multirow[t]{2}{*}{ Step length preferred DTC } & Time & 3.522 & $0.067^{t}$ & 0.27 \\
\hline & Time $\times$ intervention & 0.433 & 0.652 & 0.10 \\
\hline \multirow[t]{2}{*}{ Step length fast DTC } & Time & 5.165 & $0.028 *$ & 0.32 \\
\hline & Time $\times$ intervention & $\mathrm{I} .748$ & 0.186 & 0.20 \\
\hline \multirow[t]{2}{*}{ Step length variability preferred } & Time & 6.57 & $0.014 *$ & 0.36 \\
\hline & Time $\times$ intervention & 0.658 & 0.523 & 0.12 \\
\hline \multirow[t]{2}{*}{ Step length variability fast } & Time & 1.04 & 0.314 & 0.15 \\
\hline & Time $\times$ intervention & 0.173 & 0.842 & 0.06 \\
\hline \multirow[t]{2}{*}{ Step length variability preferred DT } & Time & 0.2 & 0.657 & 0.07 \\
\hline & Time $\times$ intervention & 0.047 & 0.954 & 0.03 \\
\hline \multirow[t]{2}{*}{ Step length variability fast DT } & Time & 0.889 & 0.351 & 0.14 \\
\hline & Time $\times$ intervention & 0.158 & 0.855 & 0.06 \\
\hline \multirow[t]{2}{*}{ Step length variability preferred DTC } & Time & 0.985 & 0.326 & 0.15 \\
\hline & Time $\times$ intervention & 0.722 & 0.492 & 0.13 \\
\hline \multirow[t]{2}{*}{ Step length variability fast DTC } & Time & 0.034 & 0.855 & 0.03 \\
\hline & Time $\times$ intervention & 0.412 & 0.665 & 0.10 \\
\hline \multirow[t]{2}{*}{ Step time preferred } & Time & 0.079 & 0.779 & 0.04 \\
\hline & Time $\times$ intervention & 1.056 & 0.357 & 0.15 \\
\hline Step time fast & Time & 3.287 & $0.077^{t}$ & 0.26 \\
\hline & Time $\times$ intervention & 3.312 & $0.046 *$ & 0.26 \\
\hline Step time preferred DT & Time & 9.355 & $0.004 * *$ & 0.42 \\
\hline & Time $\times$ intervention & 0.077 & 0.926 & 0.04 \\
\hline Step time fast DT & Time & 0.124 & 0.727 & 0.05 \\
\hline & Time $\times$ intervention & 0.67 & 0.517 & 0.12 \\
\hline Step time preferred DTC & Time & 11.028 & $0.002 * *$ & 0.45 \\
\hline & Time $\times$ intervention & 0.267 & 0.767 & 0.08 \\
\hline Step time fast DTC & Time & 3.514 & $0.068^{t}$ & 0.27 \\
\hline & Time $\times$ intervention & 1.975 & 0.151 & 0.21 \\
\hline Step time variability preferred & Time & 4.176 & $0.047 *$ & 0.29 \\
\hline & Time $\times$ intervention & 0.074 & 0.929 & 0.04 \\
\hline Step time variability fast & Time & 7.101 & $0.011^{*}$ & 0.37 \\
\hline & Time $\times$ intervention & 0.204 & 0.816 & 0.07 \\
\hline Step time variability preferred DT & Time & 1.378 & 0.247 & 0.17 \\
\hline & Time $\times$ intervention & 0.137 & 0.873 & 0.06 \\
\hline
\end{tabular}


Table S6 (Continued)

\begin{tabular}{lllll}
\hline Dependent variable & Effect & $\boldsymbol{F ( 2 , 4 4 )}$ & $\boldsymbol{P}$ two tailed & $\boldsymbol{r}$ \\
\hline Step time variability fast DT & Time & 2.702 & 0.107 & 0.533 \\
Step time variability preferred DTC & Time $\times$ intervention & 0.638 & 0.118 \\
& Time & 2.549 & 0.12 \\
Step time variability fast DTC & Time $\times$ intervention & 0.089 & 0.23 \\
& Time & 0.105 & 0.747 & 0.04 \\
\end{tabular}

Notes: Bold values indicate significance or trend. $* P<0.05$. $* * P<0.01$. ${ }^{t} P<0.10$ trend.

Abbreviations: ANOVA, analysis of variance; DT, dual-task; DTC, dual-task cost.

Table S7 Multiple regression for the linear global time effect (from the 6-month period before training, to training, to 6 months after training, $\mathrm{N}=66$ ) and the interaction between orthogonal contrasts and time effect for fall frequency

\begin{tabular}{|c|c|c|c|c|c|c|c|c|}
\hline Dependent variable & Predictor & $b$ & $95 \% \mathrm{Cl}$ & & $S E b$ & $\beta$ & $P$ two tailed & $R^{2}$-change \\
\hline \multirow[t]{4}{*}{ Fall frequency } & Linear global time effect & -0.15 & -0.24 & -0.07 & 0.04 & -0.24 & $<0.001 * * *$ & 0.056 \\
\hline & Quadratic global time effect & -0.03 & -0.08 & 0.01 & 0.02 & -0.09 & 0.165 & 0.009 \\
\hline & Linear interaction $A B \times C$ & -0.02 & -0.08 & 0.04 & 0.03 & -0.04 & 0.588 & 0.001 \\
\hline & Linear interaction $A \times B$ & 0.02 & -0.08 & 0.12 & 0.05 & 0.03 & 0.663 & 0.001 \\
\hline
\end{tabular}

Notes: Bold values indicate significance or trend. $* * * P<0.001$.

Abbreviations: A, DANCE; B, MEMORY; C, PHYS; Cl, confidence interval; DANCE, virtual reality video game dancing; MEMORY, treadmill walking with simultaneous verbal memory training; PHYS, treadmill walking; $\mathrm{SE}, \pm$ standard error.

Table S8 Multiple regression for the linear global time effect (from pretest to 6-month test, $\mathrm{N}=7 \mathrm{I}$ ) and the interaction between orthogonal contrasts and time effect for functional fitness variables

\begin{tabular}{|c|c|c|c|c|c|c|c|c|}
\hline Dependent variable & Predictor & $b$ & $95 \% \mathrm{Cl}$ & & $S E b$ & $\beta$ & $P$ two tailed & $R^{2}$-change \\
\hline \multirow[t]{3}{*}{ SPPB, total score } & Linear global time effect & 0.60 & 0.46 & 0.74 & 0.07 & 0.34 & $<0.00 I^{* * * *}$ & 0.115 \\
\hline & Linear interaction $A B \times C$ & 0.01 & -0.09 & 0.11 & 0.05 & 0.01 & 0.845 & 0.000 \\
\hline & Linear interaction $\mathrm{A} \times \mathrm{B}$ & -0.05 & -0.22 & 0.13 & 0.09 & -0.02 & 0.595 & 0.000 \\
\hline \multirow[t]{3}{*}{ SPPB, adapted balance test } & Linear global time effect & 0.27 & 0.13 & 0.41 & 0.07 & 0.15 & $<0.00 I^{* * * *}$ & 0.023 \\
\hline & Linear interaction $A B \times C$ & -0.04 & -0.13 & 0.06 & 0.05 & -0.03 & 0.471 & 0.001 \\
\hline & Linear interaction $A \times B$ & -0.09 & -0.26 & 0.09 & 0.09 & -0.04 & 0.333 & 0.002 \\
\hline \multirow[t]{3}{*}{ SPPB, five chair-rises } & Linear global time effect & -1.64 & -1.99 & -1.30 & 0.17 & -0.38 & $<0.001$ I*** & 0.141 \\
\hline & Linear interaction $A B \times C$ & -0.02 & -0.26 & 0.22 & 0.12 & -0.01 & 0.882 & 0.000 \\
\hline & Linear interaction $A \times B$ & 0.02 & $-0.4 I$ & 0.45 & 0.22 & 0.00 & 0.923 & 0.000 \\
\hline \multirow[t]{3}{*}{ SPPB, 3 m-walk } & Linear global time effect & -0.26 & -0.32 & -0.19 & 0.03 & -0.30 & $<0.001 * * *$ & 0.090 \\
\hline & Linear interaction $A B \times C$ & -0.02 & -0.06 & 0.03 & 0.02 & -0.03 & 0.503 & 0.001 \\
\hline & Linear interaction $\mathrm{A} \times \mathrm{B}$ & 0.06 & -0.02 & 0.14 & 0.04 & 0.06 & 0.152 & 0.003 \\
\hline \multirow[t]{3}{*}{ 6-min-walk, distance } & Linear global time effect & 21.32 & 15.91 & 26.74 & 2.74 & 0.18 & $<0.001 * * *$ & 0.032 \\
\hline & Linear interaction $A B \times C$ & 2.52 & -1.26 & 6.29 & 1.91 & 0.03 & 0.190 & 0.001 \\
\hline & Linear interaction $\mathrm{A} \times \mathrm{B}$ & 3.33 & -3.40 & 10.06 & 3.40 & 0.02 & 0.329 & 0.001 \\
\hline \multirow[t]{3}{*}{ 6-min-walk, RPE } & Linear global time effect & 0.54 & 0.35 & 0.74 & 0.10 & 0.26 & $<0.001 * * *$ & 0.067 \\
\hline & Linear interaction $A B \times C$ & -0.12 & -0.26 & 0.02 & 0.07 & -0.08 & $0.083^{t}$ & $0.007^{t}$ \\
\hline & Linear interaction $\mathrm{A} \times \mathrm{B}$ & 0.13 & -0.11 & 0.37 & 0.12 & 0.05 & 0.294 & 0.002 \\
\hline
\end{tabular}

Notes: Bold values indicate significance or trend. $* * * P<0.001$. ${ }^{t} P<0.10$ trend.

Abbreviations: A, DANCE; B, MEMORY; C, PHYS; CI, confidence interval; DANCE, virtual reality video game dancing; MEMORY, treadmill walking with simultaneous verbal memory training; PHYS, treadmill walking; SE, \pm standard error; SPPB, Short Physical Performance Battery; RPE, rate of perceived exertion. 
Table S9 Repeated-measures ANOVA from 6 months to follow-up test for SPPB variables, N=47

\begin{tabular}{|c|c|c|c|c|}
\hline Dependent variable & Effect & $F(2,44)$ & P two tailed & $r$ \\
\hline \multirow[t]{2}{*}{ SPPB, total score } & Time & 5.260 & $0.027 *$ & 0.33 \\
\hline & Time $\times$ intervention & 1.688 & 0.197 & 0.19 \\
\hline \multirow[t]{2}{*}{ SPPB, adapted balance test } & Time & 0.591 & 0.446 & 0.12 \\
\hline & Time $\times$ intervention & 0.336 & 0.716 & 0.09 \\
\hline \multirow[t]{2}{*}{ SPPB, five chair-rises } & Time & 2.465 & 0.124 & 0.23 \\
\hline & Time $\times$ intervention & 0.719 & 0.493 & 0.13 \\
\hline \multirow[t]{2}{*}{ SPPB, 3 m-walk } & Time & 0.154 & 0.696 & 0.06 \\
\hline & Time $\times$ intervention & 0.566 & 0.572 & 0.11 \\
\hline
\end{tabular}

Notes: Bold values indicate significance or trend. $* P<0.05$.

Abbreviations: ANOVA, analysis of variance; SPPB, Short Physical Performance Battery.

\section{Publish your work in this journal}

Clinical Interventions in Aging is an international, peer-reviewed journal focusing on evidence-based reports on the value or lack thereof of treatments intended to prevent or delay the onset of maladaptive correlates of aging in human beings. This journal is indexed on PubMed Central, MedLine,
CAS, Scopus and the Elsevier Bibliographic databases. The manuscript management system is completely online and includes a very quick and fair peer-review system, which is all easy to use. Visit http://www.dovepress. com/testimonials.php to read real quotes from published authors. 